\title{
Impacts of climate change on avian populations
}

\author{
Stéphanie Jenouvrier ${ }^{1,2}$ \\ March 27, 2013
}

Running title: 3-steps: Measuring, Understanding, Predicting

To whom correspondence may be addressed: sjenouvrier@whoi.edu.

phone:+1 5082893245

1. Biology Dept., MS-50, Woods Hole Oceanographic Institution, Woods Hole, MA 02543, USA

2. Centre d'Etudes Biologiques de Chizé, Centre National de la Recherche Scientifique, F-79360 Villiers en Bois, France

Keywords: IPCC; extreme events; climatic niche; stochastic population projection; extinction; uncertainties 


\section{Contents}

1 Introduction $\quad 4$

2 STEP 1: Measuring the effects of climate change on avian populations 7

2.1 Needs for longitudinal data. . . . . . . . . . . . . . . . . 7

2.2 Effects of climate change on population abundances. . . . . . . . . . . 8

2.3 Effects of climate change on vital rates. . . . . . . . . . . . . . 10

2.4 Summary of STEP 1. . . . . . . . . . . . . . . . . . 14

3 STEP 2: Understanding the effect of climate change on avian populations. 15

3.1 Climate-dependent population models . . . . . . . . . . . . . 16

3.2 Population growth as function of climate . . . . . . . . . . . . . . . 17

3.3 Climate mean state, variability and extreme effects . . . . . . . . . . . 19

3.4 Effects of climate on population dynamics through vital rates . . . . . . . . 21

3.5 Summary of STEP $2 \ldots \ldots \ldots \ldots$

4 STEP 3: Prediction of avian population responses to climate change 23

4.1 Goals of IPCC-class models . . . . . . . . . . . . . . . . . . . . . 24

4.2 Important characteristics of IPCC-class models . . . . . . . . . . . . . . 25

4.3 Future population responses to climate change: a handful of studies . . . . . 29

4.4 Addressing uncertainties . . . . . . . . . . . . . . . . . . . . . . . . . . . . . . . . 32

4.5 Summary of STEP $3 \ldots \ldots \ldots$. . . . . . . . . . . . . . . . . . . . . . . . . . . . .

5 CONCLUSIONS: Prospects and challenges. 36

5.1 Integrating spatial dynamics . . . . . . . . . . . . . . . . . 36

5.2 Integrating eco-evolution . . . . . . . . . . . . . . . . . . . . . . . . . . . . . . . . . . .

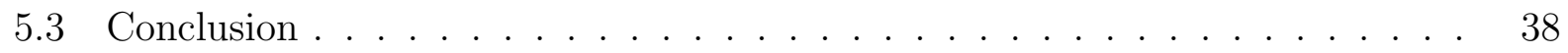

6 Acknowledgments $\quad 39$

$\begin{array}{lll}7 & \text { References } & 40\end{array}$

8 Table $\quad 57$

$\begin{array}{llr}9 & \text { Figure } & 57\end{array}$

10 Supplementary Appendix 1: Impact of extreme harsh winters on the de$\begin{array}{ll}\text { mography of the Barn Owl. } & 66\end{array}$

11 Supplementary Table 1: Prospective analysis for matrix stage structured models 


\begin{abstract}
This review focuses on the impacts of climate change on population dynamics. I introduce the MUP (Measuring, Understanding and Predicting) approach, which provides a general framework where an enhanced understanding of climate-population processes, along with improved long-term data, are merged into coherent projections of future population responses to climate change. This approach can be applied to any species, but this review illustrates its benefit using birds as examples.

Birds are one of the best-studied groups and a large number of studies have detected climate impacts on vital rates (i.e. life history traits, such as survival, maturation, or breeding, affecting changes in population size and composition) and population abundance. These studies reveal multifaceted effects of climate with direct, indirect, time- lagged and non-linear effects. However, few studies integrate these effects into a climate-dependent population model to understand the respective role of climate variables and their components (mean state, variability, extreme) on population dynamics. To quantify how populations cope with climate change impacts, I introduce a new universal variable: the "population robustness to climate change." The comparison of such robustness, along with prospective and retrospective analysis may help to identify the major climate threats and characteristics of threatened avian species.

Finally, studies projecting avian population responses to future climate change predicted by IPCC-class climate models are rare. Population projections hinge on selecting a multi-climate model ensemble at the appropriate temporal and spatial scales and integrating both radiative forcing and internal variability in climate with fully specified uncertainties in both demographic and climate processes.
\end{abstract}




\section{Introduction}

Large changes in the Earth's climate are already apparent and changes are expected to continue into the next century (Solomon et al. 2007). There is now ample evidence that individual plants and animals respond to climate change affecting population dynamics and resulting in changes of distribution and species persistence (e.g. reviews Walther 2002; Parmesan 2006; Hoegh-Guldberg \& Bruno 2010). Birds are one of the most well-studied groups, and have been shown to be very sensitive to climate change at various levels: individual (phenology, life history traits), population, species (distribution and persistence) and community (Møller et al. 2004, 2010; Wormworth \& Şekercioğlu 2011). Changes in phenology such as an advancement of laying date, or poleward and upward shifts in bird ranges have been very well-documented, but relatively less documented is the effect of climate change on populations (Crick 2004).

Climate change poses a major threat for bird populations (Møller et al. 2004, 2010; Wormworth \& Şekercioğlu 2011). There is a pressing demand for population predictions to future climate conditions in order to understand the possible impacts of climate change on avian populations and to aid implementation of necessary conservation strategies. Information about actual and potential climate change impacts can be of considerable benefit for managers to refine decisions on species conservation status (e.g. listing, delisting and jeopardy; Intersecretarial Commission on Climate Change 2007). The criteria for a species to be listed on the Red List of the International Union for the Conservation of Nature (IUCN) now includes projections of future risk to species from climate change (IUCN 2008).

IUCN found that 35\% of birds (among 9,856 bird species assessed) have traits that render them particularly susceptible to climate change impacts (Foden et al. 2008), with the most vulnerable families being seabirds (e.g. penguins (spheniscidae), albatross (diomedeidae), procellariidae (petrels and shearwater); see review of Croxall et al. 2002; Boersma 2008; Forcada \& Trathan 2009; Ainley et al. 2010; Barbraud et al. 2012; Sydeman et al. 2012). 
BirdLife International found that extreme climate events account for the largest threat to birds (Wormworth \& Şekercioğlu 2011), urging for better understanding of such effects on bird populations.

Projecting the impact of future climate change on population persistence hinges on good measurements and thorough understanding of species' susceptibility to climate change, which are critical to both the quality of science and its application to public policy (Berteaux et al. 2006). The goal of this review is to illustrate a general and comprehensive three-step approach to (1) Measure, (2) Understand and (3) Project the impacts of climate change on populations (MUP approach) using bird studies as examples.

A large number of avian studies have measured the effect of climate on population and life history traits, providing a rich understanding of the multifaceted effect of climate (STEP 1). Surprisingly, relatively few studies have integrated these effects into climate-dependent population models in order to understand the mechanisms underlying these relationships and how climate mean state and variability influence population dynamics by affecting vital rates (i.e. life history traits, such as survival, maturation or breeding, that affect changes in the size and composition of a population) (STEP 2). Such understanding of the processes is critical to develop process-oriented models and to advance predictive ecology (Evans et al. 2012). Only a handful of studies project population responses under future climate change, especially using projections from climate models contributing to the Assessment Report (AR) of the Intergovernmental Panel on Climate Change (IPCC) (STEP 3). The difference in the number of publications between these three steps reflects a major gap already identified in the IPCC fourth AR (AR4) (Parry et al. 2007): a lack of studies predicting the ecological impact of future climate change. Ecology needs to become more predictive (Evans et al. 2012) and this review emphasizes important recommendations to project population persistence under future climate change using the three-step MUP framework.

The IPCC defines climate as the "statistical description in terms of the mean and variability of relevant quantities (i.e. weather variables) over a period of time ranging from 
months to thousands or millions of years. The classical period is 30 years, as defined by the World Meteorological Organization." Thus, here, climate refers to long-term inter-annual variations of weather. Climate change refers to "a statistically significant variation in either the mean state of the climate or in its variability, persisting for an extended period (typically decades or longer)" (Solomon et al. 2007). These two definitions have two important consequences: the need to use long-term data (see STEP 1: Measuring section) and to consider both the effect of the mean state and variability of climate on bird populations, and their respective roles (see STEP 2: Understanding section).

The third step of the MUP approach focuses on projecting population responses (see STEP 3: Projection section), which is defined as making a well-informed inference on any future state variable such as population size or persistence based on facts, statistical evidence or causal relationships with fully specified uncertainties and contingent upon explicit scenarios for climate, land use, human population, technologies and economic activity (Clark 2001; Berteaux et al. 2006). The focus of projecting climate, population size or persistence using various models is not to project whether individual weather events will occur at a particular time or whether a population will go extinct a particular year, which are unpredictable on long time scales, but on the statistics of these state variables in terms of mean, trend, probability of occurrence or variability over a given time period. The acknowledgement and quantifications of uncertainties and decision risks in any attempt to project the future is vital for informing management decisions and for setting policy. This is important for maintaining public confidence and an increasing number of studies recommend embracing uncertainty to make robust predictions (Beale \& Lennon 2012). Finally, the last section outlines some important challenges and prospects for understanding and predicting avian population responses to climate change. 


\section{STEP 1: Measuring the effects of climate change on avian populations}

Climate impacts size and composition of a population by its effects on vital rates (such as survival, recruitment or breeding success). Vital rates are influenced by food acquisition and energy allocation processes in response to changes in habitat or food availability driven by climate fluctuations (Figure 1). Thus, climate influences populations via multiple pathways, involving both direct effects on vital rates and indirect effects mediated through climatic influences on habitat and prey, resulting in complex and lagged responses. Ornithology has an established history of measuring the effects of weather and climate on avian demography (Seavy et al. 2008); partly due to the great efforts by dedicated ornithologists who have collected exceptional long-term data sets over many years (Clutton-Brock \& Sheldon 2010a; Møller \& Fiedler 2010a). Effects of climate change on population abundances and vital rates have been detected for many bird species, including passerine birds, waders, seabirds, waterfowl and raptors (Sæther \& Engen 2010; Wormworth \& Şekercioğlu 2011).

\subsection{Needs for longitudinal data.}

To measure the effect of climate change on avian populations, long-term data are needed (Clutton-Brock 2010, 2010a; Møller \& Fiedler 2010a). Longitudinal censuses provide insights on the effect of climate on avian population size (Lack 1966; Perrins et al. 1991; Newton 1998) and a time series analysis is a robust approach to describe population trends and variability in response to climate change (Lindström \& Forchhammer 2010; Clutton-Brock \& Sheldon 2010). However, such studies have some limitations in identifying the causes of population fluctuations because it is difficult to disentangle the respective roles of changes in breeding success, survival, emigration and immigration (Clutton-Brock \& Sheldon 2010).

Longitudinal individual-based studies enable the measurement and understanding of how climate influences the various vital rates of birds' life history. Individual-based studies over 
a decade are not rare for birds (especially passerines such as tits and flycatchers), and a handful of studies have even been going on for more than 50 years (e.g. Great Tits (Parus major) in the Netherlands: Reed et al. 2012, Visser et al. 2004; seabirds in the Southern Ocean: Barbraud et al. 2012; and Swiss Barn Owls (Tyto alba): Altwegg et al. 2006).

\subsection{Effects of climate change on population abundances.}

First, numerous studies have shown that avian populations are affected by local climate variables (e.g. temperature, rainfall and wind) and large-scale atmospheric indices (e.g. North Atlantic Oscillation: NAO; El Niño (EN) tied to the atmospheric phenomenon Southern Oscillation (SO): ENSO; Stenseth et al. 2002, 2003). For example, species less tolerant to warm climates showed the sharpest declines between 1980 and 2005 among 110 common birds breeding across Europe (Jiguet et al. 2010).

Second, the variability of climate has strong consequence on avian population dynamics. Oscillations in local climate or atmospheric indices may drive population cycles. Jenouvrier et al. (2005c) showed that populations and demographic parameters of three Antarctic seabirds fluctuate with a periodicity of 3-5 years that was also detected in sea-ice extent and the SO index.

Extreme weather events are a special case of variability and can have tremendous effects on avian populations. Extreme events are rare and according to the IPCC: "an extreme weather event would normally be as rare as or rarer than the 10th or 90th percentile." In an ecological context, extreme events can be characterized by statistical extremity, timing, and abruptness (a function of magnitude over duration) relative to the life cycle of the species affected (Jentsch et al. 2007). Detecting the effects of extreme events on avian populations is extremely difficult due to the lack of long-term data on the appropriate time scale. Most evidence comes from particular events such as hurricane, droughts and floods. For example, Hurricane Hugo destroyed $70 \%$ of the nesting trees of the largest population

of the endangered Red-cockaded Woodpecker (Picoides borealis) (see review of Moreno \& 
Møller 2011).

Climate regime shifts, i.e. an abrupt change from a stationary climate state to another (Hare \& Mantua 2000) also impact avian populations. Both Arctic species, Thick-billed Murre (Uria lomvia) and temperate species, Common Murre (Uria aalge) declined during large sea surface temperature (SST) shifts that were linked to two climate regime shifts in 1977 and in 1989 (Irons et al. 2008). The mid-1970s regime shift was the largest recorded in the Northern Hemisphere because both the NAO and the North Pacific Oscillation shifted from a negative to a positive regime.

Third, population responses to climate may vary across season and some bird species may be more sensitive to a particular season. For migrant species, population responses to climate are constrained by different climate conditions during the breeding and nonbreeding season (Small-Lorenz et al. 2013). Species breeding in Europe but wintering in Africa experience larger population declines than those that are more sedentary, suggesting a stronger effect of climate conditions at the wintering grounds for some long-distance migrant bird species (Peach et al. 1991; Thaxter et al. 2010). Studies have also examined the respective effects of climate variation during the breeding season and non-breeding season on populations in the context of the "tub-hypothesis" and "tap-hypothesis" (Lack 1966; Sæther 2004; Sæther \& Engen 2010). The "tub-hypothesis" proposes that climate variations during the non-breeding season influence fluctuations in population size because climate conditions determine the number of birds surviving over winter in combination with density dependence. The "tap-hypothesis" proposes that climate variations during the breeding season influence fluctuations in population size because climate variations will influence the inflow of new recruits into the population the following year. Although the population fluctuations of altricial birds are most affected by factors occurring during the non-breeding season ("tap hypothesis") and nidifuguous birds by factors occurring during the reproductive season ("tub" hypothesis) (Sæther et al. 2004), Sæther \& Engen (2010) concluded that drawing a general pattern among birds is impossible due to the interplay of climate effects 
on vital rates, lagged responses and covariation among vital rates.

Fourth, avian population responses to climate can lag due to climatic, ecological or demographic processes. For example, ecological lags may occur through food web effects such as in polar sea ice ecosystems (Thomas \& Dieckmann 2003; Smetacek \& Nicol 2005). Antarctic Sea ice during winter affects the recruitment of Antarctic Krill (Euphausia superba) the following summer (Atkinson et al. 2004), resulting in higher abundance of prey for Antarctic seabirds breeding the next summer (Fraser and Hofmann 2003; Trivelpiece et al. 2011).

Recruitment processes may also drive lagged effects of climate (Thompson \& Ollason 2001). A general analysis of 29 seabird species suggested that the North Atlantic Oscillation (NAO) had negative effects on population size through adult survival, but positive effects through lagged effects on offspring recruitment (Sandvik et al. 2012). The NAO effects on populations are stronger through recruitment, and the long time lags involved for longlived seabirds make their detection difficult, suggesting that its magnitude may still be underestimated (Sandvik et al. 2012).

On the other hand, birds may respond to a predictable climatic event well in advance. For example, populations of Sooty Terns (Onychoprion fuscatus) and Common Noddies (Anous stolidus ) declined when the $20^{\circ} \mathrm{C}$ thermocline deepened, which is a signal of an up-coming El Niño event (Devney et al. 2009). During El Niño years, unfavorable warm waters block the nutrient-rich upwelling, disrupting the entire ecosystem from the abundance and distribution of phytoplankton, zooplankton and fishes to seabirds. The mechanism underpinning this population decline is likely that seabirds skip breeding during El Niño years rather than compromising their survival and future opportunity to reproduce.

\subsection{Effects of climate change on vital rates.}

The previous section highlighted several examples of population response to climate. However, it is important to measure climate effects on vital rates to understand the processes 
that determine population response to climate change (Figure 1).

First, there are numerous studies documenting strong effects of climate on various vital rates. The majority of studies focus on the effect of local and/or large-scale atmospheric indices on reproduction and/or survival of adult birds. For example, Frederiksen et al. (2007) showed a negative effect of SST on the breeding productivity of Black-legged Kittiwake (Rissa tridactyla). Grosbois et al. (2006) detected effects of local temperature and precipitation as well as a large-scale tropical index (rainfall in the Sahel) on adult survival of Blue Tits (Parus caeruleus). The most studied climatic variables are temperature and precipitation, but the choice of variables depends on the environment of the species, its life history and available meteorological measurements. For example, sea ice is an important driver of vital rate variations in polar ecosystems and adult survival of Emperor and Adélie penguins is related to sea ice (Barbraud and Weimerskirch 2001; Ballerini et al. 2009; Emmerson \& Southwell 2011). Westerly wind in the Southern Ocean is an important driver of breeding success of Wandering Albatross (Diomedea exulans) because wind influences their foraging efficiency and in turn their body condition and breeding performance (Weimerskirch et al. 2012).

Several studies have investigated multiple vital rates across the entire life cycle showing the complex interplay between season, climate variables and vital rates. Sillett et al. (2000) measured the effect of El Niño Southern Oscillation on the survival, fecundity and recruitment of Black-throated Blue warblers (Dendroica caerulescens). They showed that El Niño Southern Oscillation has a two-fold effect on warblers, affecting both their survival in the tropics as well as their reproductive performance in the north.

Although a large number of studies focus on adult survival and fecundity parameters, juvenile survival, recruitment, breeding propensity and dispersal are equally important to understand population responses to climate, but are less well-documented. Juvenile survival and probability of recruitment have been less studied because it is difficult to obtain estimates for long lived species with delayed maturity when they are not observable on breeding 
grounds, such as seabirds (Jenouvrier et al. 2008a), and when a large proportion of individuals never return to the study population, such as Lesser Kestrel (Falco naumanni) (Mihoub et al. 2010). Interestingly, recruitment and juvenile survival are likely to be more affected by climate variations than adult survival, because adult survival variations are buffered against environmental variations for long-lived species (e.g. Blue-footed Booby (Sula nebouxii), Oro et al. 2010). For seabirds, another critical parameter is the probability of skipping breeding during years when the climate is unfavorable (Jenouvrier et al. 2005b) and Cubaynes et al. (2011) found that Red-footed Boobies (Sula sula) are more likely to skip breeding in El Niño years. Dispersal remains the most difficult parameter to estimate, and studies detecting an effect of climate change on dispersal are rare. Dugger et al. (2010) estimated a low dispersal of breeding Adélie Penguins $(<1 \%)$ and showed an increase by more than three-fold during years of difficult sea ice conditions.

Second, most studies of the effects of climate on vital rates documented indirect effects through availability of habitat or food resources (Figure 1). For example, breeding performance of the Rhinoceros Auklet (Cerorhinca monocerata) declines in warmer spring SST years because recruitment of the Auklet's prey, the sand lance, is temperature-dependent. As spring SSTs increased, the occurrence of sand lance in chicks' diet decreased as well as chicks' growth rate (Hedd et al. 2006).

However, adverse weather conditions and extreme events can also directly impact birds' vital rates. High temperature can cause heat stress and low temperature hypothermia, both of which can reduce birds' breeding success and adult survival. Droughts, storms and cyclones can kill birds while heavy rainfall can flood nests and burrows killing chicks (Bolger et al. 2006, Demongin et al. 2010; Chambers et al. 2011; Moreno \& Møller 2011). For example, an extreme large flood of the Lower Mississippi River in 1993 destroyed all eggs, chicks and fledglings of the least tern (Sterna antillarum) (Dugger et al. 2002). More importantly, adverse weather conditions and extreme events can simultaneously affect several vital rates with dramatic consequence for the population. For example, Altwegg et al. (2006) showed 
that two extreme harsh winters simultaneously reduced juvenile and adult survival rates for the Swiss Barn Owl (Tyto alba) (Figure 2). During harsh winters the snow cover duration is longer, making small mammals unavailable for Barn Owls to hunt.

Third, many studies documented non-linear relationships between climate and vital rates (e.g. Cassin's Auklets (Ptychoramphus aleuticus): Lee et al. 2007). Because climate conditions tolerated by a species are limited due to physiological and ecological constraints most studies have detected a bell-shaped relationship (e.g. Adélie Penguin (Pygoscelis adeliae): Ballerini et al. 2009; Emmerson \& Southwell 2011; White Stork (Ciconia ciconia): Schaub et al. 2005; Nevoux et al. 2008).

Fourth, a climate variable can have opposite effects on different vital rates (e.g. Eurasian Oystercatcher (Haematopus ostralegus): van de Pol et al. 2010). For example, sea ice extent impacts survival and fecundity of Emperor Penguins (Aptenodytes forsteri) in opposite ways (Barbraud \& Weimerskirch 2001). During years with extensive winter sea ice, food is likely more abundant the following summer, increasing adult survival. However, foraging trips are longer in extensive sea ice years resulting in fewer hatched eggs.

Finally, the effect of climate varies among seasons and various phases of the life cycle as well as between individuals. Several studies have shown that vital rate responses to climate change may vary between individuals for example, according to their age (Oro et al. 2010; Pardo et al. 2012), sex (Barbraud \& Weimerskirch 2001a; Grosbois \& Thompson 2005), breeding experience (Nevoux et al. 2008) and habitat quality (Dugger et al. 2005; van de Pol et al. 2010). For example, Nevoux et al. (2008) showed that the survival and breeding success of inexperienced Black-browed Albatross (Thalassarche melanophrys) breeders is affected by climatic conditions while the survival of experienced breeders is not impacted.

One of the most striking examples of seasonal climate effects over different phases of the annual life cycle is the effect of climate on vital rates of Great Tits breeding in the Netherlands. Vital rates are affected by summer caterpillar abundance and the autumnal beech (Fagus sylvatica) crop, both of which are driven by climate fluctuation. Beech crops 
are an important winter food source affecting the overwinter survival of juvenile and adult Great Tits (Grotan et al. 2009). Caterpillar abundance during summer has an indirect effect on breeding vital rates through a phenological mismatch effect (Visser et al. 1998, 2004). In the Netherlands, advancements in laying dates in response to warmer springs have been insufficient to keep pace with stronger advancements in caterpillar phenology resulting in a population that now breeds much later relative to the seasonal peak in caterpillar abundance (Visser et al. 2003, 2005). Such a mismatch (i.e. late breeding relative to the caterpillar food peak date) affects Great Tit probability of double-brooding, fledgling success, offspring recruitment and the number of recruits (Reed et al. 2012).

\subsection{Summary of STEP 1.}

To summarize this first step, there is a huge number of avian studies detecting an effect of climate on populations and vital rates, especially adult survival and reproduction. It reveals multifaceted effects of climate with direct, indirect, lagged and non-linear effects. Climate can act in opposite directions on different vital rates, and its effects vary across different seasons and phases of the life cycle, as well as between individuals due to their differences e.g. in age, sex, experience.

Most of the effects of climate on vital rates are indirect and future effort entails measuring the factors governing these relationships (e.g. determining the impact of food abundance and foraging strategies on vital rates). An increasing effort should also be devoted to measuring the effect of climate on juvenile survival, recruitment, breeding propensity and dispersal, especially since tremendous improvements in statistical analyses allows for addressing issues of low sample size and detectability (e.g. capture-recapture frequentists or Bayesian approaches with unobservable and multi-states models: Williams et al. 2002; Thomson et al. 2009). Further research is critically needed on dispersal processes because they may eventually drive extinctions and colonizations of local populations and species persistence in the face of future climate change. 
Each population response to climate effects reflect the unique combination of meaningful climate factors and species life history across different spatial and temporal scales. Several studies have proposed some general biological traits or characteristics inherent to species particularly vulnerable to climate change: those with small populations and range size, specialists, poor dispersers and migratory species (see Foden et al. 2008), but a quantitative framework is crucially needed. Thoughtful comparison requires the development and application of common dimensionless variables quantifying how populations can cope with climate impacts (e.g. "population robustness to climate change" see STEP 2).

\section{STEP 2: Understanding the effect of climate change on avian populations.}

The next step of the MUP approach is to understand the net effects of a specific change in climate on population dynamics, which are not predicted by simply measuring the effect of individual climate variables on individual vital rates (Ådahl et al. 2006, Zeigler 2013). This requires to integrate the measured effects of climate on populations and vital rates into a population model. The relationship between the population growth rate and climate provides critical information on a species' ability to cope with climate change, and here I introduce the concept of "population robustness to climate change". Furthermore, comparing the respective role of climate factors and their statistical components (mean versus variability) may provide thoughtful insight for our understanding of the effects of climate change on population dynamics. Finally, it is important to integrate the effects of climate on vital rates in a population model to better understand the mechanisms. The population growth rate may be relatively insensitive to some vital rates strongly affected by climate variations, or there might be counteracting influences of climate on the population growth rate due to changes in vital rates responding to the same climate variable in opposite directions. 


\subsection{Climate-dependent population models}

Understanding the processes by which climate influences avian populations requires developing climate-dependent population models. There are various approaches ranging from non-structured population models (Lande et al. 2003) and structured population models (Caswell 2001) to individual-based modeling (Grimm \& Railsback 2005).

First, it is important to consider the assumptions behind climate-dependent population models. Deterministic models assume that population and vital rates follow a determined path, which may or may not be driven by climate time series. Stochastic models integrate random variations caused by demographic stochasticity, environmental stochasticity or by sampling and uncertainties about parameter estimates (see STEP 3). Demographic stochasticity is an individual's chance of surviving or dying, reproducing or not reproducing; while environmental stochasticity is temporal variations of the probability to survive and reproduce (Caswell 2001; Lande et al. 2003; Boyce et al. 2006). Environmental stochasticity can be caused by random climate variations or other environmental factors. Thus, a model could be stochastic by including demographic stochasticity or environmental stochasticity without incorporating random variability in climate itself.

Another important assumption is the stationarity of the environment, i.e. the environment fluctuates but its statistical properties (mean, variance, autocorrelation) do not change over time. Most deterministic and stochastic population models assume that the environment is stationary, however climate is not. To include the non-stationarity of the climate, a time series of the non-stationary environment could be used to project vital rates and population trajectories (e.g. Gotelli \& Ellison 2006).

Second, it is important to include in climate-dependent population models appropriate processes which may interact with climate and influence population dynamics: densitydependence, migration, environmental stochasticity generated by processes other than climate, and demographic stochasticity for small populations (Caswell 2001; Lande et al. 2003; see comprehensive review in Sæther \& Engen 2010). For example, Grotan et al. (2009) 
showed that the population size of Great Tits was strongly affected by the combined effect of the temporal variation in the number of recruits produced locally as well as the number of immigrants, which are both affected by food abundance (beech crop), temperature, densitydependence and environmental stochasticity. Recruitment contributed more to population fluctuation than immigration, and variations in recruitment were more influenced by beech crop and temperature than density dependence effects.

Last but not least, it is crucial to integrate the effects of climate across the entire life cycle because they can differ among seasons (Altwegg \& Anderson 2009), phase and stages of the life cycle (Jenouvrier et al. 2010) and can impact vital rates in a variety of ways (van de Pol et al. 2010). Although studies quantifying the effect of individual climate variables on individual vital rates from STEP 1 are critical to understand the effect of climate on the species life cycle and are necessary to parametrize population models of STEP 2, they do not provide a complete understanding of the population's responses to climate change. Examining only one or few vital rates can lead to erroneous predictions of population responses to climate change (Zeigler 2013), such as for migratory birds (Small-Lorenz et al. 2013). Adahl et al. (2006) demonstrated that an increase in survival and/or reproduction due to climatically induced increases in the resources do not necessarily lead to an increase in population size owing to the combined effects of demography, density dependence and behavioural mechanisms filtering the information about the resources (e.g. possible use of environmental cues).

\subsection{Population growth as function of climate}

To understand how a species may cope with climate change and establish comparisons among species, studying the population growth as a function of climate is a powerful approach (Figure 3). This is very similar to the concept of the "climatic niche" which represents the climatic conditions that are suitable for species persistence and is driven by species physiological tolerances (e.g. lethal physiological temperatures). The climatic niche breadth has 
important implications on species responses to climate change (e.g. Tingley et al. 2009; Monahan \& Tingley 2012). If the relationship between population growth and climate variations is inferred from a single local population, inference at the species level and climatic niche is based on the Janzen hypothesis (Janzen 1967; Quintero \& Wiens 2012). Janzen assumes that the overall realized climatic niche breadth of a species is set by the temporal variations of climate within-locality and thus spatial variation in climatic conditions is relatively unimportant. This hypothesis has been rarely tested, but Quintero \& Wiens (2012) found that within-locality seasonal variation explains most variation in climatic niche breadths among 409 species of frog, lizards and salamanders.

Similarly to the climatic niche breadth, the range of climatic conditions, $C_{a}^{*}$, where the population is capable of increase (i.e. where the intrinsic population rate of increase $r$ is positive) can inform the ability of a species to cope with climate change. Eury- species (wide $C_{a}^{*}$, e.g. eurythermal species for temperature) may cope better with future climate change than steno- species (narrow $C_{a}^{*}$ ) because they may have a greater chance of having a population that may grow under shifting climate conditions. To compare the width range of climatic conditions where the population is growing, I propose to express the climate covariates $C$ as proportional anomalies $\left(C_{a}\right)$ relative to the mean. Such a dimensionless variable allows for the comparison between various climate variables and species. They can be calculated as:

$$
C_{a t}=\frac{C_{t}-\bar{C}}{\bar{C}}
$$

where $C_{t}$ is the climate covariate in year $t$ and $\bar{C}$ the mean of $C$ over a specified period of time (usually relative to a present time window of several decades).

In addition to quantifying the climatic range where the population can persist, the relationship between population growth and climate quantifies how fast a population can grow for a specified range of climate conditions $r^{*}$. In other words, it measures the population's ability to withstand or recover from difficult climate conditions and how much extra- environmental deterioration a population can tolerate within $C_{a}^{*}$ (Figure 3). To integrate both 
$C_{a}^{*}$ and $r^{*}$, I define the "population robustness to climate change" as the area of the region in the $r-C_{a}$ plane of Figure 3 bounded by the curve $r\left(C_{a}\right)$ and over the interval $C_{a}^{*}=\left[C_{1}, C_{2}\right]$. The "population robustness to climate change", noted $R$, is computed using integral calculus as:

$$
R=\int_{C_{1}}^{C 2} r\left(C_{a}\right) d C_{a}
$$

To compare "population robustness to climate change" among short and long-lived species, life expectancy must be considered. Indeed, there is a gradient of life history traits among species resulting in a slow-fast continuum of population growth rates (e.g. in birds: Sæther \& Bakke 2000). Thus, a measure of population growth is given by: re(0); where $e(0)$ is the life expectancy. Under the umbrella of matrix stage structured models, e(0) can easily be calculated (Caswell 2001 section 5).

\subsection{Climate mean state, variability and extreme effects}

Climate is changing, both in term of its mean state and its variability (Solomon et al. 2007) and both components affect population dynamics in complex ways (Boyce et al. 2006). In a small songbird population, the dipper (Cinclus cinclus), Sæther et al. (2000a) showed that half of the environmental stochasticity was explained by variation in mean winter temperature. An increase in mean winter temperature of $2.5^{\circ} \mathrm{C}$ increased the expected population size by $58 \%$ at carrying capacity and the average population size from 117 to 184 in a non-linear relationship.

Climate variability can have different impacts on population dynamics than climate mean state; thus it is important to adopt a stochastic climate approach. Only three avian studies (on Blue Cranes (Anthropoides paradiseus): Altwegg \& Anderson (2009); Eurrasian Oystercatchers: van de Pol et al. 2010; Emperor Penguins: Jenouvrier et al. 2012) have studied the role of climate mean states and variability. Van de Pol et al. (2010) and Jenouvrier (2012) have concluded that the effect of variability is smaller than the effect of the mean states of climate. This is similar to the results found for the effect of temporal variability on 
vital rates: the sensitivity of population growth rates to standard deviations of vital rates is much lower than the sensitivity to mean vital rates (Morris et al. 2008). Temporal variance in the vital rates is known to reduce the stochastic population growth rate but variations in climate do not necessarily decrease the stochastic growth rate. Indeed, potentially non-linear relationships between vital rates and climate variables may lead to the opposite pattern: a positive effect of climate variability on the stochastic growth rate (Boyce et al. 2006; Morris et al. 2008; Koons et al. 2009). The effects of an increase of sea ice concentrations (SIC) variance on Emperor Penguin population growth rates can be positive or negative depending on the mean state of SIC (Jenouvrier et al. 2012). Higher rainfall variability during the early breeding season results in a small increase of Blue Cranes population growth due to the nonlinear relationship between rainfall and reproduction (Altwegg \& Anderson 2009). Finally, an increase in climate variance could increase the strength of covariation between vital rates, which can have a large effect on the population growth rate (Boyce et al. 2006). For example during extreme events, several vital rates can be affected in the same direction, having a dramatic impact on population size.

The effects of extreme climatic events, however, have been poorly studied despite an increasing awareness of dramatic impacts on wildlife populations (IPCC Special Report on Extreme Events, Easterling et al. 2000). Plus, extreme events are rare, which means there is little data available to make assessments regarding changes in their frequency or intensity. Some bird studies have explored the effect of extreme variability in vital rates on populations, such as the effect of extreme mortality on European Shag (Phalacrocorax aristotelis) (Frederiksen et al. 2008) and Barn Owl (Altwegg et al. 2006) populations; and of the extreme massive breeding failures on population recovery of Emperor Penguins (Jenouvrier et al. 2009b). However, those studies did not directly integrate the effect of extreme climatic events on population dynamics (but see Van de Pol et al. 2010, Nuur et al. 2012) and the effects of extreme events frequency and intensity have yet to be explored. Figure 2 shows the effects of the frequency of extreme harsh winters on a population of Barn 
Owl using the exceptional long term data of Altwegg et al. (2006). When there is not a harsh winter, the population increases $\sim 2 \%$ per year. With the actual frequency of harsh winter ( 2 events among 58 years $=0.035$ ), the population is projected to decrease by $\sim 2 \%$ per year. When the frequency of harsh winters increases, the stochastic population growth rate declines dramatically.

\subsection{Effects of climate on population dynamics through vital rates}

The way climate may drive population dynamics depends on a complex interplay of how the population growth rate (hereafter noted $\lambda$ ) is impacted by changes in vital rates and the amplitude of vital rate fluctuations induced by climate variations. Life- history theory predicts that phenotypic plasticity and selection processes lead to a reduction in the environmentally induced variance of a life history trait having a high impact on $\lambda$ (Caswell 1983), which has been called "environmental canalization theory" (Gaillard \& Yoccoz 2003). Several avian studies have shown that the vital rates to which $\lambda$ are most sensitive show small temporal variations (Sæther and Bakke 2000) and are less affected by climate variations (Nevoux et al. 2007, 2010; Oro et al. 2010). Van de Pol et al. (2010) found that juvenile survival was more variable in time and more affected by winter temperature than adult survival for the Eurasian Oystercatchers, in agreement with the "environmental canalization theory." However, the population dynamic was more affected by change in climate on adult survival (the canalized trait) than juvenile survival, emphasizing the importance of conducting a full demographic analysis with both prospective and retrospective analyses to quantify the potential impact of vital rates and the contribution of their climate-induced variations on $\lambda$.

A prospective analysis (known also as perturbation or sensitivity) enables a projection of the consequences of future or hypothetical changes in the vital rates and climate factors on the population growth rate (Caswell 2000, see supplementary Table S1). For example, Peery et al. (2012) detected effects of both temperature and precipitation on vital rates of 
Mexican Spotted Owl (Strix occidentalis). Using a climate-dependent population model and conducting a sensitivity analysis they showed that $\lambda$ is more sensitive to temperature than precipitation. Thus, future change of temperature will have a greater impact than change in precipitation on the Spotted Owl population growth rate. Stochastic sensitivity analysis (Tuljapurkar et al. 2003; Haridas \& Tuljapurkar 2005; Caswell 2005) can disentangle the effect of the mean and variance of individual environmental drivers on the stochastic growth rate and thus is very useful to compare the respective effects of climate mean state and variability.

A retrospective analysis sheds light on how variation in each of the vital rates has contributed to an observed variation in the population growth rate (Caswell 2000). For example, in long-lived species such as Emperor Penguin, $\lambda$ is more sensitive to changes in adult survival than breeding success (Jenouvrier et al. 2005a). However, a retrospective analysis shows that adult survival and breeding success variations contribute equally to past population growth variations. During the late 70 s, a dramatic $50 \%$ population decrease was caused by a decline in adult survival (especially males) due to an unusually low sea ice extent (Barbraud \& Weimerskirch 2001; Jenouvrier et al. 2010). After the 80s, it is the increased frequency in massive breeding failure, probably due to years with extensive sea ice extent (Massom et al. 2009), that hinders the population from recovering (Jenouvrier et al. 2009b). To measure variations in $\lambda$ as a function of (co)variation in the vital rates and climate, life table response experiment (LTRE) methods and other kinds of variance decomposition can be applied, both in deterministic and stochastic environments (Caswell 2000, 2010; Davison et al. 2010). For stochastic analysis, Caswell (2010) focuses on the contributions of variation in the environmental components (e.g. autocorrelation) and of population-specific responses of vital rates to these environmental changes. Davison et al. (2010) focus on the contributions of differences in the mean and the variance of the vital rates. Thus, deterministic and stochastic LTRE approaches provide useful tools to explore the effects of climate statistical components (mean, variance, extreme, auto-correlation) on population growth rate. 


\subsection{Summary of STEP 2}

To summarize this second step, integrating the measured effects of climate change into a climate-dependent population model permits a thorough understanding of the processes by which climate affects population growth and fluctuations. Modeling tools and information to parametrize models from STEP 1 are available, yet there are relatively few studies exploring the respective effects of climate variables, and their components (mean state, variability, extreme) on population dynamics.

Drawing general patterns along the life history gradient, among behavioural traits (migrant versus resident) or foraging traits (specialists versus generalists), across taxonomic levels or communities and across climatic zones, may help to identify the major climate threats and threatened avian species. However, such analysis is hampered by the lack of a universal variable quantifying how a population may cope with climate impacts. The "population robustness to climate change" as well as prospective and retrospective analyses provide such common tools. Prospective and retrospective analyses have proven their powerful application in the context of the "environmental canalization theory" to infer a general pattern of the effects of vital rate variations on population growth across a life history gradient. Future research entails incorporating the effect of climate mean states and variability; especially since variations in climate do not necessarily translate into similar effects of vital rate variations on the population growth. Finally, process-oriented models including the climate change impacts on vital rates, may help to move forward a predictive ecology (Evans et al. 2012, see STEP 3).

\section{STEP 3: Prediction of avian population responses to climate change}

Although efforts to project population responses to climate change are increasing, this is still a nascent field (Wormworth \& Şekercioğlu 2011, see publication date on Table 1). 
Climate model simulations included into the assessment reports of the IPCC are a primary means of analyzing climate dynamics and making skillful predictions of future climate change based on state-of-the-art process-oriented climate models. In addition, the IPCC framework permits to include the various sources of uncertainty ranging from future greenhouse gas emission levels to climate modeling. This section describes various approaches to project population responses using climate predictions from IPCC climate models and a handful of avian case studies. The aim is not to criticize the specific approaches chosen in these examples, but instead to reveal the critical challenges of developing an effective and innovative applications of IPCC-class climate models to project population responses to climate change.

\subsection{Goals of IPCC-class models}

It is important that ecologists improve their knowledge of climate models, emissions scenarios and the capabilities and limitations of climate projections (Seavy et al. 2008). Coupled Atmosphere-Ocean General Circulation Models (AOGCMs) that contributed to the last IPCC Scientific Assessment of Climate Change (2007) incorporate detailed representations of the atmosphere, land surface, oceans and sea ice. Climate change may be due to natural internal processes or external forcing, or to persistent anthropogenic changes in the composition of the atmosphere or in land use. The Earth's energy balance (i.e difference between absorbed solar energy and emitted infrared radiation into space) is affected by a "forced change," which is a combination of natural (e.g. solar, orbital changes, volcanoes) and anthropogenic forcings (e.g. greenhouse gases, many classes of aerosols). IPCC-class models maintain the global energy balance, and changes in climate can arise due to changes in the "forced change" or due to internal variations in the climate system, referred as "natural variability."

The first goal of climate modeling is to understand the processes that control the most important climate features (such as temperature, precipitation, windiness and storminess) and predict the dynamics of these features over long time scales. The focus of climate 
modeling is not on individual weather events, which are unpredictable on long time scales, but on the statistics of these events in terms of mean and variability over a period of time ranging from months to thousands or millions of years, and on the slow evolution of oceans and ice sheets (Bader et al. 2008).

The second goal of climate modeling is to predict future climate change using various scenarios of future climate forcing and anthropogenic responses to implement mitigation strategies. Impacts of climate change on the environment and society will depend not only on the response of the Earth systems to changes in radiative forcing, but also on how human societies respond through changes in technology, economies, lifestyle and policy. The last IPCC AR4 is based on the Special Report on Emissions Scenarios (SRES 2000), but the upcoming AR5 is using the new Representative Concentration Pathway (RCP) scenarios (van Vuuren et al. 2011). The RCP are no longer defined by the IPCC but developed by a special group, and differ from SRES by assuming various levels of mitigation. RCP incorporate the complete path from socio-economic $\rightarrow$ greenhouse gas emissions $\rightarrow$ long-lived greenhouse gas abundances $\rightarrow$ forcing of mean climate change. Different climate scenarios

should be used to explore the potential ecological consequences of various climate change mitigation strategies (Visser 2008; Moss et al. 2010), but bird studies that have done so to predict future population responses are rare (but see Barbraud et al. 2010; Perry et al. 2012, Table 1).

\subsection{Important characteristics of IPCC-class models}

There are important characteristics of AOGCM climate simulations and real climate system that should be considered carefully when attempting to project population persistence under future climate scenarios:

- there are several AOGCMs and a multi-model ensemble is a set of AOGCMs using the same "forced change" (i.e. scenario);

- the resolution of climate output is larger than the scale at which ecological processes 
occur;

- models differ in their ability to reproduce the climate and "Each model tends to simulate some aspects of the climate system well and others not so well, and each model has its own set of strengths and weaknesses." (Knutti 2008); and

- both internal variability and radiatively forced changes are important components of the real climate system (Stock et al. 2011).

Thus, projecting population responses to climate change using AOGCM outputs requires (i) using a multi-model ensemble, (ii) extracting the climate output at appropriate temporal and spatial scales, (iii) selecting the appropriate set of models for which the statistical property of the forecasted climate variables agrees well with past observations (known as hindcasting) and (iv) the need to account for both internal variability and radiatively forced changes because climate changes evident at any time and location will be a combination of these two sources.

First, the biologically relevant climate forecasts should be extracted from various IPCCclass models because combining different models exploits the strength of diverse approaches and yields a more appropriate estimate of the uncertainties (Meehl et al. 2007). Although nearly all AOGCMs use the same set of primitive dynamical physical equations, model structural differences arise by different numerical algorithms to solve dynamical physical equations and different approximations, as well as differences in spatial resolutions and configurations of model grids (Bader et al. 2008). Ideally, a set of model simulations from structurally different models using the same forcing but where one or more initial condition ensembles are available from each model should be considered, which is known as multi-model ensembles (Tebaldi \& Knutti 2007). IPCC-class model outputs are freely available from the archive of coupled model output at the Program for Climate Model Diagnosis and Intercomparison (PCMDI, http://www-pcmdi.1lnl.gov/) (Meehl et al. 2007), with a set of coordinated simulations from more than 20 AOGCMs. Outputs are categorized by variables (e.g. temperature, precipitation), scenario (i.e. climate experiment) and climate models. Each file 
contains a single output variable (along metadata) from a single model and a single simulation (i.e., from a single ensemble member of a single climate experiment) over specified time periods (historical "control run" or future scenarios) and scales (e.g. month) and specified spatial grid covering the entire surface of the globe. Metadata contains the coordinate/grid variables, time variables and variable attributes (names, description, dimensions) and follows the NetCDF Climate and Forecast (CF) Metadata Convention.

Secondly, the temporal and spatial scales of the variables of interest should be chosen carefully given the resolution of AOGCMs. The temporal and spatial scales at which ecological processes occur are usually finer than the coarse grid of AOGCMs, or the temporal resolution at which climate outputs are saved (due to computational constraints). There are two approaches to address this issue: either using climate covariate at a larger spatial scale than the scale at which the ecological processes occurs assuming it is a good proxy of local climate or downscaling climate projections. Jenouvrier et al. (2012) used the first approach, and showed that sea ice concentration at large spatial scale is a good proxy of local sea ice characteristic affecting the life cycle of emperor penguins. Downscaling methods such as statistical downscaling or regional climate models may help to obtain finer-scaled climate data (Bader et al. 2008; Seavy et al. 2008, but see Racherla \& Shindell 2012). For example, Wolf et al. (2010) used a regional climate model to forecast changes in the California Current upwelling ecosystem, especially SST and upwelling intensity, to predict the future population growth rate of Cassins Auklets. Regional climate models are driven by boundary conditions from AOGCM, and several AOGCM(s) should be ideally used (Pierce et al. 2009).

Third, there is no "best model," and climate simulations from various state-of-the-science AOGCMs differ. Defining a unique overall figure of merit of a climate model, i.e. metric or skill score for its ability to predict future climate change, is extremely difficult and debated (Knutti 2008). Thus, selecting a set of climate models depends of the climate variable of interest and the ability of climate models to simulate past climate observations gives us some confidence in their ability to simulate the future. AOGCMs forced with observed 
natural and anthropogenic forcings are able to simulate the observed 20th century global mean temperature well, with typical correlations between models and observations of $95 \%$ or better. Other climate variables are still problematic, and for precipitation, the correlation between seasonal means of models and observations is $50 \%$ to $60 \%$ on scales of a few hundred kilometers (Bader et al. 2008). Therefore, ecologists should compare the statistical properties of the climate "control run" projection to observations in order to select the most appropriate multi-model ensembles (Tebaldi \& Knutti 2007; Knutti et al. 2010) at relevant temporal and spatial scales.

Finally, it is important to take into account climate changes generated by both the "forced change" and natural variability. For example, an average over a set of models may provide climate simulation superior to any individual model and climatologists have used such averaged ensembles to study the "forced change" signal. However, for assessing the ecological impact of climate change, it is important to integrate the change in natural variability (see STEP 2).

To illustrate the importance of considering an ensemble of several selected climate models rather than focusing on a single model, Figure 4a shows the Emperor Penguin population trajectories obtained from sea ice concentrations (SIC) predicted by different climate models. Those five AOGCMs were selected among 20 models for their ability to most accurately reproduce the statistical properties of past sea ice observations (Jenouvrier et al. 2012). If the study had used only the climate model "ukmo-hadcm 3" to predict the Emperor Penguin population persistence by 2100 in Terre Adélie, it would have concluded that Emperor Penguins are not threatened by climate change. On the contrary with "cccma-cgcm 3- 1," the probability that the population declines by more than $90 \%$ by 2100 (noted $P_{e}$ ) is $99 \%$. Including all selected climate models, the conclusion ranges between these two extremes $\left(P_{e} \sim 43 \%\right)$.

Ecological studies often forecast future climate change based on the predicted climate mean state by AOGCMs (e.g. Peery et al. 2012) because these values are very easily 
accessible in publications (e.g. Solomon et al. 2007). Figure 4b shows the Emperor Penguin population projections obtained using such an approach. Under these assumptions, Emperor Penguins are not threatened by climate change. These contrasting results emphasizes the importance of incorporating the natural variability, the non-stationary and tipping point dynamic predicted by a time series of climate models.

Finally, ecological studies often use the averaged climate ensemble (e.g. Barbraud et al. 2010), ignoring the change in natural climate variability. Figure 4c illustrates how these different assumptions can lead to different outcomes when predicting the population response of Emperor Penguins. Although the effect of climate mean state is greater than the effect of variability on population growth rate (see STEP 2), climate variability still plays an important role in population dynamics as shown by the different population trajectories projected using "forced change" versus "forced change + natural variability."

\subsection{Future population responses to climate change: a handful of studies}

There are relatively few studies projecting bird populations (Table 1). Among them, two-thirds of the populations are projected to decline if climate changes as predicted by IPCC-class climate models. Ominously, those projected to decline include: Snowy Plover threatened by sea level rise (Aiello-Lammens et al. 2011); Emperor and Adélie Antarctic Penguins by sea ice decline (Ainley et al. 2010; Jenouvrier et al. 2009a, 2012); Black-Browed Albatross by warmer SSTs (Barbraud et al. 2010); Tidal Marsh Song Sparrows (Melospiza melodia) by high sea-level rise and extreme high tide (Nur et al. 2012); Mexican Spotted Owls by wetter and hotter climates in Arizona and New Mexico (Peery et al. 2012) and Cassins Auklet by warmer SSTs and reduced upwelling intensity of the California upwelling system (Wolf et al. 2010). One may wonder if the predominance of population decline projections results from a publication bias toward "doom and gloom" scenarios. Evidently, one could also be tempted to conclude that there will be more losers than winners under 
future climate change. To answer this question, more studies are critically needed.

These studies differ in the approach adopted for projecting population responses to climate using a range of combinations including anticipating, forecasting or predicting climate and populations in the future. Berteaux et al. (2006) distinguish anticipation, forecasting and prediction for inferences based respectively on facts, statistical evidence or causal relationships, but acknowledge that projections are often based on mixed approaches. Ainley et al. (2010) anticipate that predicted sea ice habitat loss may jeopardize Antarctic penguin colonies north of $70^{\circ}$ S, i.e. $50 \%$ of Emperor colonies (40\% of breeding population) and $75 \%$ of Adélie colonies (70\% of breeding population). Drever et al. (2011) forecast the population responses of four duck species to future snow cover duration in the western boreal forest of North America and show that late-nesting duck species will experience the most severe population declines. Wolf et al. (2010) predict that the Auklet population growth rate will experience an absolute decline of up to $45 \%$ if future SST and upwelling intensity change as predicted by a regional model in 2080-2099.

Table 1 illustrates that ecologists are putting great effort into developing population models accounting for demographic processes to predict population trajectories (nine of 10 used structured-matrix population models following Caswell 2001). They are also including important features of climate models: $\sim$ half used an ensemble of models (averaged or not), three used different scenarios and four did their own climate model selection. Finally, half of the 10 studies reviewed focused on forced change and $\sim$ half integrated some natural variability, either using the one predicted by climate model or observed variability.

While most of the approaches discussed in STEP 2 assume stationary climate conditions, climate change is not stationary, and both the mean state and variability change over time. All studies from Table 1 have acknowledged the non-stationary aspect of climate change, either by using IPCC time series predictions to fully incorporate non-stationary climate processes (e.g. Jenouvrier et al. 2009a, 2012; Barbraud et al. 2010), or by forecasting the trend of climate averages predicted by IPCC-class models (e.g. Peery et al. 2012, Nur et al. 
2012), or by focusing on restricted periods where the climate conditions are assumed to be stationary (e.g. a 20-year window for Wolf et al. 2010; a 30-year window for Drever et al. 2011).

Studies directly linking IPCC time series to avian population models are rare (but see Jenouvrier et al. 2009a, 2012; Barbraud et al. 2010). Nonetheless, this approach enables an integration of the pathway of change in mean state and variability in climate, as well as tipping points and extreme event dynamics. Barbraud et al. (2010) linked a stochastic population model to deterministic climate projections and showed that future population responses are contrasted among three seabirds breeding in the Southern Ocean. Blackbrowed Albatross' quasi-extinction is projected by 2100, while the Amsterdam Albatross (Diomedea amsterdamensis) population is projected to increase steadily.

It is also important to include some stochasticity in climate when using time series from IPCC-class models, because climate models do not aim to project climate in a particular year, but rather the change in statistical properties, mean state and variances over time. Ideally, this would be obtained from multiple stochastic realizations of each IPCC-class model, but such output are limited from few to a couple of tens runs. For the Emperor Penguin, Jenouvrier et al. (2009a) obtained stochastic climate forecasts by discretizing the climate into two states ("warm" and "regular") and applying a nonparametric binary regression to calculate the forecast frequencies of warm events (see also Hunter et al. 2010 for Polar Bear). For continuous climate variables, Jenouvrier et al. (2012) developed a novel approach using smoothed temporal means, variances and covariances from the predicted climate outputs.

Finally, only one study explored specifically the effect of an increased frequency of extreme climatic events while projecting population responses to future climate conditions (Nur et al. 2012; although Van de Pol et al. integrated effect of extreme flooding events in their analysis on the Oystercatcher). To project population of Tidal Marsh Song Sparrow for the San Francisco Estuary, Nur et al. (2012) included the frequency of extreme tides resulting from sea-level rise and/or severe storms in addition to the impact of temperature and 
precipitation forecasted by a downscaled AOGCM and sea-level rise predicted by a regional climate model (Stralberg et al. 2011). Extreme high tides were the most significant climate factor threatening long-term viability of Song Sparrows due to nest loss from flooding.

\subsection{Addressing uncertainties}

To move forward a predictive ecology, there is a wide range of uncertainties from climate to ecological processes that needs to be addressed through a dialogue involving scientists, managers and policy makers (Clark 2001; Ruete et al. 2012; Sutherland \& Freckleton 2012; Evans 2012).

Communicating the degree of uncertainty to the public and policy makers is a critical part of the next AR5. AR5 incorporates two major criteria: the confidence in the validity of a finding and quantified measures of uncertainty or likelihood scale. The first criteria is qualitative and based on the evidence (limited, medium, robust) and agreement statements (low, medium, high). It incorporates the "type, amount, quality, and consistency of evidence (e.g. mechanistic understanding, theory, data, models, expert judgment) and the degree of agreement" (Mastrandrea et al. 2010; Mastrandrea \& Mach 2011). The second criteria quantifies "probabilistic estimates of the occurrence of outcomes associated with, unless otherwise noted, high or very high confidence" (Mastrandrea et al. 2010; Mastrandrea \& Mach 2011). It varies from exceptionally unlikely (0-1\% probability) to virtually certain (99-100\% probability).

Quantified measures of uncertainty in population viability have been addressed by calculating the "quasi-extinction probability" or the prediction interval for the population size (Lande et al. 2003). The "quasi-extinction probability" is the probability that the population will decline by more than a specific "quasi-extinction threshold" over a specific time horizon. Population prediction interval (PPI) is a stochastic interval of population size that includes the unknown population size with a given probability $(1-\alpha)$ over the entire time horizon of interest. PPI avoid the subjective choices of a specific time horizon and quasi- 
extinction threshold, but not the choice of $\alpha$. Chatfield (2001) recommended $\alpha=10 \%$, a compromise between lower and higher $\alpha$-PPIs. Higher $\alpha$-PPIs are better calibrated for their robustness for outliers and to departures from model assumptions. Lower $\alpha$-PPIs provide higher confidence than higher $\alpha$-PPIs but show heavy tails.

They are diverse sources of uncertainties when projecting population responses to climate change ranging from climate to demography (Figure 5), which can be addressed in a hierarchical process (McGowan 2011). They can be organized in three main categories: data, model and prediction uncertainties. Climate and demographic data are often observed incompletely with large uncertainty caused by observation and measurement errors. This adds to the temporal variance process some uncertainty in parameter estimates, which is a major component of the second source of uncertainty: model uncertainty. In addition, model uncertainties include structural uncertainties in the model specification and the models initial and boundary conditions. Structural uncertainty arises from competing scientific theories and simplifications of reality such as inclusion or exclusion of density dependence in population models. The last main source of uncertainty is related to prediction and includes uncertainties on future system drivers and future no-analog climate conditions.

To incorporate uncertainties related to future socio-economic development and emissions/ abundance of greenhouse gas, several RCP scenarios should be incorporated. Ecologists may also want to include uncertainty into decision-making frameworks related to other factors than climate (Evans 2012; Milner-Gulland 2012). For example, Nur et al. (2012) evaluated different management strategies to improve nest survival of Song Sparrow (by reducing predator populations or access to tidal marsh nesting habitat), which can reverse projected population declines caused by future sea-level rise and extreme high tide events.

Because population projections are contingent on data and model uncertainties in climate, it should be incorporated by using a climate multi-model ensemble and a forecasting approach to build stochastic climate forecasts. Tebaldi \& Knutti (2007) argue that integration of all aspects of climate model uncertainty requires using multi-model ensembles, which sample 
initial condition, parameter as well as structural uncertainties in the model design. It is possible to include uncertainties in the selection of this multi-model ensemble by attributing some weights for each climate model by using the historical relationship between predictions and observations and then sample the number of future stochastic climate forecasts according to these model weights. However, the determination of such weights are still controversial as it is difficult to quantify model skill and derive model weights accordingly (Knutti et al. 2010, Weigel et al. 2010).

Demographic data uncertainty caused by observation and measurement errors may bias estimates of many population parameters or vital rates, which parametrize population models (see review in Morris \& Doak 2002). Many statistical methods are available to quantify such uncertainty in parameter estimations, such as variance decomposition, separating sampling from process variance in temporal variations of vital rates (e.g. Gould \& Nichols 1998) or maximum likelihood statistical methods (e.g. De Valpine \& Hastings 2002) to Bayesian Markov chain Monte Carlo (e.g. Clark \& Bjørnstad 2004; Clark 2007) in time series analysis. Parameter uncertainty may reduce our ability to precisely predict future population fluctuations (Ellner \& Fieberg 2003; Holmes et al. 2007; Ellner \& Holmes 2008) and several avian studies have highlighted the importance of including parameter uncertainty when making future population projections (e.g. Song Sparrow: Sæther 2000; Barn Swallow (Hirundo rustica): Engen et al. 2001; Piping Plover (Charadrius melodus): McGowan 2011). Including the uncertainties in both demographic parameters and model structure, involve model selection, model averaging or both (Clark 2001, Burnham \& Anderson 2002). For example, in the framework of capture- recapture models and maximum likelihood statistical methods, Hunter et al. (2010) developed a method to account for both uncertainty in model selection and parameter uncertainty while preserving the covariances among vital rates in population projections. Albeit with quite extensive numerical work in most cases, the Bayesian paradigm provides powerful new tools which could embrace unknown levels of error, mixture of models, model selection and averaging (Clark \& Gelfand 2006; Gimenez et al. 2009). These models 
allow unknown levels of errors to propagate through various submodels (Cressie et al. 2009) as well as integrate multiple stochastic elements (environmental, demographic stochasticity as well as individual heterogeneity) (Clark 2001, 2005).

There are few studies comparing the different sources of uncertainties. Using data from several passerine species, Sæther et al. (2009) studied the effect of different demographic sources of uncertainties on future population projections. They showed that including observation error in the models improves precision in density-independent population predictions and reduces bias for density-dependent population models. In addition, ignoring demographic stochasticity resulted in positively biased population size predictions and imprecise density-independent population predictions. Studies comparing the respective role of the different sources of uncertainties on population projections in response to climate change are rare (but see Ruete et al. 2012). The main source of uncertainties for the Emperor Penguin population (Jenouvrier, unpublished result), as well as in the population of bryophyte (Buxbaumia viridis) (Ruete et al. 2012) is the "AOGCM formulation." This result emphasizes the importance of using several AOGCMs for predicting future population responses.

\subsection{Summary of STEP 3}

To summarize this last step, predicting population responses to climate change are now possible thanks to a tremendous advancement in our understanding of the demographic processes, and the availability of climate predictions from IPCC-class models. There are, however, large uncertainties in population and climate predictions. Ecologists sometimes see wide population prediction intervals as indicating "failure" either to fit the right model or to get a usable interval, but prediction intervals could be misleadingly narrow by failing to incorporate the appropriate uncertainty. Uncertainties in data and the model structure could be eventually reduced by improving sampling efforts, our knowledge of the processes and refining models (i.e. by continuous feedback between the three steps of the MUP approach). Situations where uncertainties are large and information content too low to make useful 
management decisions now could become more informative within a decade by developing new or supporting existing long term data (STEP 1), as well as improving knowledge and refining demographic models (STEP 2). Stochasticities and non-linearities of any ecological system results in uncertainties inherent in predictive ecology, but as Clark (2001) stated: "Large inherent uncertainty does not necessarily neutralize efforts to anticipate change." To address inherent uncertainties, ecologists should incorporate the natural variability and nonstationarity of climate processes, which can have a tremendous impact on population dynamics and devote more effort in using multi-model climate ensembles instead of one particular climate model. To provide information to decision-makers and help implement mitigation strategies, several climate scenarios should be incorporated, as well as the inclusion of other drivers than climate change. Indeed, the impact of climate change will interact with other stressors such as habitat destruction, introduced species, overexploitation and extinction cascades (chains of extinctions) and effective mitigation conservation strategies may focus on local stressors rather than climate change.

\section{CONCLUSIONS: Prospects and challenges.}

\subsection{Integrating spatial dynamics}

Avian population responses to climate change have often been analyzed in terms of the effect of local climate conditions on temporal population fluctuations at a particular location. However, if negative effects of climate variations on vital rates and populations occur simultaneously over large geographical areas, the consequences for population viability will be more severe than if they occur only locally (Sæther \& Engen 2010). Climate can induce population synchrony if variations in climate are autocorrelated in space and if populations had the same density-dependent structure known as the "Moran effect" (Moran 1953; Royama 1992). Synchrony is of particular concern for assessing the impact of climate change because species persistence is strongly related to population synchrony. Spatial synchrony has been detected for numerous avian populations, but attributing the "Moran effect" has 
been difficult (see review of Sæther \& Engen 2010). Climate can also induce synchrony in vital rate variations and Jenouvrier et al. (2008b) have shown that adult survival variations of Cory's shearwater (Calonectris diomedea) are synchronized among six populations spread across $4600 \mathrm{~km}$. These synchronous variations are explained by Southern Oscillation Index fluctuations suggesting strong effect of climate at large spatial scales on Cory's shearwater adult survival during the nonbreeding period.

On the other hand, the effect of the same climate variable may show different directions among different populations. Various population responses to climate may result from an interaction between climate and population growth along a latitudinal or environmental gradient (see review Sandvik et al. 2008; Barbraud et al. 2012) or a spatial heterogeneity in the interaction between climate with other environmental and demographic factors (see review Sæther \& Engen 2010).

Integrating spatial dynamics will also be critically needed to adequately understand and predict how species may cope with climate change because individuals may move permanently to other locations, where climate and associated habitat conditions are more suitable. Temperature isoclines will, in general, move poleward in latitude and upward in altitude, resulting in changes in local population abundance, local extinction and colonization of new habitats, species range shifts (Parmesan 2006) and species extinctions (Thomas et al. 2004). Birds with high fertility and high dispersal rates may be able to cope with climate change by expanding or contracting their range at the right speed, while birds with lower fertility and limited dispersal rates may not (Schippers et al. 2011). For philopatric species, the colonization of new habitats with favorable climate conditions may occur through the dispersal of pre- breeders. At Lancelin Island, five pairs of Common Noddies pioneered a colony in 1991 and the population stabilized around 1,200 pairs by 2008 (Wormworth \& Şekercioğlu 2011). Further research should focus on a better understanding of dispersal processes in response to climate change (but see Dugger et al. 2010) and the development of metapopulation models integrating climate impacts or species distribution models including demographic processes 
(but see Keith et al. 2008; Anderson et al. 2009; Schippers et al. 2011).

\subsection{Integrating eco-evolution}

Species may cope with climate change by adapting to the new local climate conditions (either through micro-evolution or phenotypic plasticity). Although, there is an increasing agreement that evolutionary processes may play a crucial role for population persistence under future climate change, we know surprisingly little about how changes in climate translate into adaptive phenotypic change (see review of Pelletier et al. 2009, Reed et al. 2010, Gonzales et al. 2012, Hanski 2012). Eco-evolutionary approaches are now being developed (e.g. Coulson 2006, 2011; in a climate change context see Baskett et al. (2009), Jenouvrier \& Visser 2011). For example, Reed et al. (2012) explored how populations of sockeye salmon (Oncorhynchus nerka) can persist under scenarios of future river warming and evolutionary changes in migration timing. But such approaches have yet to be applied to avian populations.

\subsection{Conclusion}

To conclude, the MUP approach provides a general framework within which enhanced understanding of climate-population processes, along with improved long term data, are merged into coherent projections of future population responses to climate change. Projecting population responses is not the major endeavor nor a finality in itself; instead I advocate striving for a richer understanding of the various eco-evolutionary processes in which populations can cope with climate change, through pursuing/ establishing new long term studies, an invaluable source for the MUP approach. Applying the MUP approach using universal quantitative variables (e.g. "population robustness to climate change") to a broad range

of species may provide the foundations to infer general patterns across climatic zones, life history strategies, communities or ecosystems. 


\section{Acknowledgments}

This research was supported by the Grayce B. Kerr Fund and the Penzance Endowed Fund in Support of Assistant Scientists, as well as by a grant from the Ocean Life Institute at Woods Hole Oceanographic Institution. I am indebted to: Henri Weimerskirch, Christophe Barbraud, Hal Caswell and Marika Holland for their guidance, as well as fruitful discussions. I am also very grateful to L. Aubry, K. Dugger, B-E. Sæther, T Reed and several anonymous reviewers who provided thoughtful comments on earlier version of the manuscript. The Emperor Penguin data come from a long-term study supported by Expéditions Polaires Françaises, by Institut Paul Emile Victor (Programme IPEV 109), and by Terres Australes et Antarctiques Françaises. I acknowledge the efforts of all the wintering fieldworkers involved in the long-term monitoring programs in Terre Adélie since 1963, and thank Dominique Besson and Karine Delord for the management of the database. I thank also the Swiss Ornithological Institute, which encourage people to ring the Barn Owls and manage the data. Finally, I acknowledge the climate modelling groups, the Program for Climate Model Diagnosis and Intercomparison (PCMDI) and the WCRPs Working Group on Coupled Modelling (WGCM) for their roles in making available the WCRP CMIP3 multi-model dataset. Support of this dataset is provided by the Office of Science, US Department of Energy. 


\section{References}

Ådahl E, Lundberg P \& Jonzen N (2006) From climate change to population change: the need to consider annual life cycles. Global Change Biology, 12, pp. 1627-1633.

Aiello-Lammens ME, Chu-Agor ML, Convertino M, Fischer RA, Linkov I \& Akcakaya HR (2011) The impact of sea-level rise on Snowy Plovers in Florida: integrating geomorphological, habitat, and metapopulation models. Global Change Biology, 17(12), pp. 3644-3654.

Ainley D, Russell J, Jenouvrier S, Woehler E, Lyver P, Fraser W \& Kooyman G (2010) Antarctic penguin response to habitat change as Earth's troposphere reaches 2 degrees above preindustrial levels. Ecological Monographs, 80, pp. 49-66.

Altwegg R, Roulin A, Kestenholz M \& Jenni L (2006) Demographic effects of extreme winter weather in the barn owl. Oecologia, 149(1), pp. 44-51.

Altwegg R \& Anderson MD (2009). Rainfall in arid zones: possible effects of climate change on the population ecology of blue cranes. Functional Ecology, 23(5), pp. 1014-1021.

Anderson BJ, Akcakaya HR, Araujo MB, Fordham DA, Martinez-Meyer E, Thuiller W \& Brook BW (2009) Dynamics of range margins for metapopulations under climate change. Proceedings of the Royal Society, B, 276, pp. 1415-1420.

Atkinson A, Siegel A, Pakhomov E \& Rothery P (2004) Long-term decline in krill stock and increase in salps within the Southern Ocean. Nature, 432, pp. 100-103.

Bader D, Covey C, Gutowski W et al. (2008) Climate Models: An Assessment of Strengths and Limitations, Synthesis and Assessment Product 3.1. Report by the U.S. Climate Change Science Program and the Subcommittee on Global Change Research.

Ballerini T, Tavecchia G, Olmastroni S, Pezzo F \& Focardi S (2009) Nonlinear effects of winter sea ice on the survival probabilities of Adlie penguins. Oecologia, 161(2), pp. 253-265. 
Barbraud C, Rivalan P, Inchausti P, Nevoux M, Rolland V \& Weimerskirch H (2010) Contrasted demographic responses facing future climate change in Southern Ocean seabirds. Journal of Animal Ecology, 80(1), pp. 89-100.

Barbraud C, Rolland V, Jenouvrier S, Nevoux M, Delord K \& Weimerskirch H (2012) Effects of climate change and fisheries bycatch on Southern Ocean seabirds: a review. Marine Ecology Progress Series, 254, pp. 285-307.

Barbraud C \& Weimerskirch H (2001) Emperor penguins and climate change. Nature, 411, pp. 183-186.

Baskett ML, Gaines SD \& Nisbet, RM. (2009). Symbiont diversity may help coral reefs survive moderate climate change. Ecological Applications, 19(1), pp. 317.

Beale C \& Lennon J (2012) Incorporating uncertainty in predictive species distribution modelling. Philosophical Transactions of the Royal Society B: Biological Sciences, 367(1586), pp. $247-258$.

Berteaux D, Humphries MM, Krebs CJ et al. (2006) Constraints to projecting the effects of climate change on mammals. Climate Research, 32, pp. 151-158.

Boersma PD (2008) Penguins as Marine Sentinels. BioScience, 58(7), pp. 597-607.

Boyce MS, Haridas C, Lee C, Boggs CL et al. (2006) Demography in an increasingly variable world. Trends in Ecology and Evolution, 21, pp. 141-148.

Burnham K \& Anderson D (2002) Model Selection and Multimodel Inference: A Practical Information-theoretic Approach. Springer (Eds.)

Caswell, H. (2000). Prospective and retrospective perturbation analyses: their roles in conservation biology. Ecology, 81, pp. 619-627

Caswell H (2001) Matrix population models. Vol. Second, Sinauer, Sunderland, Massachusetts.

Caswell H (2005) Sensitivity analysis of the stochastic growth rate: three extensions. Australian N.Z.J.Statistical, $\mathbf{4 7}$, pp. 75-85. 
Caswell H (2007) Sensitivity analysis of transient population dynamics. Ecology Letters, 10, pp. $1-15$.

Caswell H (2008) Perturbation analysis of nonlinear matrix population models. Demographic research, 18, pp. 59-116.

Caswell H (2010) Life table response experiment analysis of the stochastic growth rate. Journal of Ecology, 98(2), pp. 324-333.

Caswell H (2011) Matrix models and sensitivity analysis of populations classified by age and stage: a vec-permutation matrix approach. Theoretical Ecology.

Caswell H \& Kaye T (2001) Stochastic demography and conservation of an endangered perennial plant (Lomatium bradshawii) in a dynamic fire regime. Advances in Ecological Research, 32, pp. 1-51.

Caswell H \& Shyu E (2012) Sensitivity analysis of periodic matrix population models. Theoretical Population Biology (C), pp. 1-11.

Chambers LE, Devney CA, Congdon BC, Dunlop N, Woehler EJ \& Dann P (2011) Observed and predicted effects of climate on Australian seabirds. Emu, 111(3), pp. 235-251.

Chatfield C (2001) Prediction Intervals. Principles of Forecasting: A Handbook for Researchers and Practitioners (ed. Armstrong JS), Kluwer Academic, Boston.

Clark JS (2001) Ecological Forecasts: An Emerging Imperative. Science, 293(5530), pp. 657-660.

Clark JS (2007) Models for Ecological Data. An Introduction. Princeton University Press, Princeton.

Clark JS (2005) Why environmental scientists are becoming Bayesians. Ecology Letters, 8, pp. 2-14.

Clark JS \& Bjrnstad ON (2004) Population time series: process variability, observation errors, missing values, lags, and hidden states. Ecology, 85, pp. 31403150.

Clark JS \& Gelfand AE (2006) A future for models and data in ecology. Trends Ecol. Evol., 21, pp. 375-380. 
Clutton-Brock T \& Sheldon BC (2010) Individuals and populations: the role of long-term, individual-based studies of animals in ecology and evolutionary biology. Trends in Ecology $\&$ Evolution, 25(10), pp. 562-573.

Clutton-Brock T \& Sheldon BC (2010) The Seven Ages of Pan. Science, 327(5970), pp. 1207-1208.

Coulson T, Benton TG, Lundberg P, Dall SRX \& Kendall BE (2006) Putting evolutionary biology back in the ecological theatre: a demographic framework mapping genes to communities. Evolutionary Ecology Research, 8, pp. 1155-1171.

Coulson T, Macnulty DR, Stahler DR, Vonholdt B, Wayne RK \& Smith DW (2011) Modeling Effects of Environmental Change on Wolf Population Dynamics, Trait Evolution, and Life History. Science, 334, pp.1275-1278.

Cressie N, Calder C, Clark J, Ver Hoef J \& Wikle C (2009) Accounting for uncertainty in ecological analysis: the strengths and limitations of hierarchical statistical modeling. Faculty of Informatics - Papers, pp. 553-570.

Crick H (2004) The impact of climate change on birds. Ibis, 146, pp. 48-56.

Croxall J, Trathan P \& Murphy E (2002) Environmental change and antarctic seabirds populations. Science, 297, pp. 1510-1514.

Cubaynes S, Doherty PF, Schreiber EA \& Gimenez O (2011) To breed or not to breed: a seabird's response to extreme climatic events. Biology Letters, 7(2), pp. 303-306.

Davison R, Jacquemyn H, Adriaens D, Honnay O, de Kroon H \& Tuljapurkar S (2010) Demographic effects of extreme weather events on a shortlived calcareous grassland species: stochastic life table response experiments. Journal of Ecology, 98, pp. 255-267.

Demongin L, Poisbleau M, Strange I \& Quillfeldt P (2010) Effects of severe rains on the mortality of southern rockhopper penguin (Eudyptes chrysocome) chicks and its impact on breeding success. Ornitologa Neotropical, 21, pp. 439-443.

De Valpine P \& Hastings A (2002) Fitting population models incorporating process noise and observation error. Ecological Monographs, 72, pp. 5776. 
Devney CA, Short M \& Congdon BC (2009) Sensitivity of tropical seabirds to El Niño precursors. Ecology, 90, pp. 1175-1183.

Drever MC, Clark RG, Derksen C, Slattery SM, Toose P \& Nudds TD (2011) Population vulnerability to climate change linked to timing of breeding in boreal ducks. Global Change Biology, 18(2), pp. 480-492.

Dugger K, Ryan MR, Galat DL, Renken RB \& Smith JW. (2002), Reproductive success of the interior least tern (Sterna antillarum) in relation to hydrology on the Lower Mississippi River, River Research and Applications 18(2), 97-05.

Dugger KM, Ainley DG, Lyver PO, Barton K \& Ballard G (2010) Survival differences and the effect of environmental instability on breeding dispersal in an Adélie penguin metapopulation. Proceedings of the National Academy of Sciences, 107(27), pp. 12375-12380.

Dugger K, Wagner F, Anthony R \& Olson G (2005) The relationship between habitat characteristics and demographic performance of Northern Spotted Owls in Southern Oregon. Condor, 107(4), pp. 863-878.

Ellner SP \& Fieberg J (2003) Using PVA for management despite uncertainty: effects of habitat, hatcheries, and harvest on salmon. Ecology, 84, pp. 1359-1369.

Ellner SP \& Holmes EE (2008) Commentary on Holmes et al. (2007): resolving the debate on when extinction risk is predictable. Ecology Letters, 11, pp. E1E5.

Emmerson L \& Southwell C (2011) Adélie penguin survival: age structure, temporal variability and environmental influences. Oecologia.

Easterling DR (2000). Climate Extremes: Observations, Modeling, and Impacts. Science, 289(5487), pp. 20682074.

Engen S, Sæther B-E \& Møller AP (2001) Stochastic population dynamics and time to extinction of a declining population of barn swallows. Journal of Animal Ecology, 70, pp. 789-797.

Evans MR (2012) Modelling ecological systems in a changing world. Philosophical Transactions of the Royal Society B: Biological Sciences, 367(1586), pp. 181-190. 
Foden W, Mace G, Vié J-C, Angulo A et al. (2008) The 2008 Review of The IUCN Red List of Threatened Species. IUCN Gland (eds Vié J-C, Hilton-Taylor C \& Stuart S), chapter Species susceptibility to climate change impacts, Switzerland.

Forcada J \& Trathan PN (2009) Penguin responses to climate change in the Southern Ocean. Global Change Biology, 15(7), pp. 1618-1630.

Fraser W \& Hofmann E (2003) A predator's perspective on causal links between climate change, physical forcing and ecosystem response. Marine Ecology Progress Series, 265, pp. $1-15$.

Frederiksen M, Daunt F, Harris MP \& Wanless S (2008) The demographic impact of extreme events: stochastic weather drives survival and population dynamics in a long-lived seabird. Journal of Animal Ecology, 77(5), pp. 1020-1029.

Frederiksen M, Edwards M, Mavor RA \& Wanless S (2007) Regional and annual variation in black-legged kittiwake breeding productivity is related to sea surface temperature. Marin, 350, pp. 137-143.

Gaillard J \& Yoccoz N (2003) Temporal variation in survival of mammals: a case of environmental canalization? Ecology, 84, pp. 3294-3306.

Gimenez O, Bonner SJ, King R et al. (2009) WinBUGS for population ecologists: Bayesian modeling using Markov chain Monte Carlo methods. Modeling Demographic Processes In Marked Populations, 3, pp. 883-915.

Gonzalez A, Ronce O, Ferriere R \& Hochberg ME. (2012). Evolutionary rescue: an emerging focus at the intersection between ecology and evolution. Philosophical Transactions of the Royal Society B, 368(1610), pp. 2012040420120404.

Gotelli N \& Ellison A (2006) Forecasting Extinction Risk With Nonstationary Matrix Models. Ecological Application, 16, pp. 51-61.

Grimm V \& Railsback S (2005) Individual-based Modeling and Ecology. Princeton Series in Theoretical and Computational Biology, (eds Grimm V \& Railsback S). 
Grosbois V, Henry P-Y, Blondel J, Perret P, Lebreton J-D, Thomas DW \& Lambrechts MM (2006) Climate impacts on Mediterranean blue tit survival: an investigation across seasons and spatial scales. Global Change Biology, 12(12), pp. 2235-2249.

Grosbois V \& Thompson P (2005) North Atlantic climate variation influences survival in adult fulmars. Oikos, 109(2), pp. 273-290.

Grotan V, Saether B-E, Engen S, van Balen JH, Perdeck AC \& Visserree ME (2009) Spatial and temporal variation in the relative contribution of density dependence, climate variation and migration to fluctuations in the size of great tit populations. Journal of Animal Ecology, 78(2), pp.447-459.

Gould WR \& Nichols JD (1998) Estimation of temporal variability of survival in animal populations. Ecology, 79, pp. 2531-2538.

Hannah L (2010) A Global Conservation System for Climate-Change Adaptation. Conservation Biology, 24(1), pp. 70-77.

Hanski I. (2012). Eco-evolutionary dynamics in a changing world. Annals of the New York Academy of Sciences, 1249(1), pp. 117.

Hare S \& Mantua N (2000) Empirical evidence for a North Pacific regime shifts in 1977 and 1989. Progress in Oceanography, 47, pp. 103-145.

Haridas CV \& Tuljapurkar S (2005) Elasticities in variable environments: properties and implications. American Naturalist, 166, pp. 481-495.

Hedd A, Bertram DF, Ryder JL \& Jones IL (2006) Effects of interdecadal climate variability on marine trophic interactions: rhinoceros auklets and their fish prey. Marine Ecology Progress Series, (309), pp. 263-278.

Hoegh-Guldberg O \& Bruno JF (2010) The Impact of Climate Change on the Worlds Marine Ecosystems. Science, 328(5985), pp. 1523-1528.

Holmes EE, Sabo JL, Viscido SV \& Fagan WF (2007) A statistical approach to quasiextinction forecasting. Ecology Letters, 10, pp. 1182-1198. 
Hunter C, Caswell H, Runge M, Regehr E, Amstrup S \& Stirling I (2010) Climate change threatens polar bear populations: a stochastic demographic analysis. Ecology, 91, pp. 2883-2897.

Hunter C, Møller H \& Fletcher D (2000) Parameter uncertainty and elasticity analyses of a population model: setting research priorities for shearwaters. Ecological Modelling, 134, pp. 299-323.

Irons DB, Anker-Nilssen T, Gaston AJ et al. (2008) Fluctuations in circumpolar seabird populations linked to climate oscillations. Global Change Biology, 14(7), pp. 1455-1463.

Janzen DH (1967) Why mountain passes are higher in the tropics. The American Naturalist, 101, pp. 233-249.

Jentsch A, Kreyling J, \& Beierkuhnlein C (2007). A new generation of climate-change experiments: events, not trends. Frontiers in Ecology and the Environment, 5(7), pp. $365-374$.

Jenouvrier S, Barbraud C \& Weimerskirch H (2005a) Long-term contrasted responses to climate of two Antarctic seabirds species. Ecology, 86, pp. 2889-2903.

Jenouvrier S, Barbraud C, Cazelles B \& Weimerskirch H (2005b) Modelling population dynamics of seabirds: importance of the effects of climate fluctuations on breeding proportions. Oikos, 108, pp. 511-522.

Jenouvrier S, Weimerskirch H, Barbraud C, Park Y-H \& Cazelles B (2005c) Evidence of a shift in cyclicity of Antarctic seabirds dynamics link to climate. Proceedings of the Royal Society of London B, 272, pp. 887-895.

Jenouvrier S, Tavecchia G, Thibault J, Choquet R \& Bretagnolle V (2008a) Recruitment processes in long-lived species with delayed maturity: estimating key demographic parameters. Oikos, 117, pp. 620-628.

Jenouvrier S, Viallefont A, Vidal P et al. (2008b) Global climate patterns explain range-wide synchronicity in survival of a migratory seabird. Global Change Biology, 14, pp. 1-12. 
Jenouvrier S, Caswell H, Barbraud C, Holland M, Strœeve J \& Weimerskirch H (2009a) Demographic models and IPCC climate projections predict the decline of an emperor penguin population. Proceedings of the National Academy of Sciences, 106, pp. 18441847.

Jenouvrier S, Barbraud C, Weimerskirch H \& Caswell H (2009b) Limitation of population recovery: a stochastic approach to the case of the emperor penguin. Oikos, 118, pp. $1292-1298$.

Jenouvrier S, Caswell H, Barbraud C \& Weimerskirch H (2010) Mating Behavior, Population growth, and the operational sex ratio: A Periodic two-sex model approach. The American naturalist, 175, pp. 739-752.

Jenouvrier S \& Visser M (2011) Climate change, phenological shifts, eco-evolutionary responses and population viability: toward a unifying predictive approach. Journal of Biometeorology, 458, pp. 1-15.

Jenouvrier S, Holland M, Stroeve J, Barbraud C, Weimerskirch H, Serreze M \& Caswell H (2012) Effects of climate change on an emperor penguin population: analysis of coupled demographic and climate models. Global Change Biology, 18, pp. 2756-2770.

Jiguet F, Gregory RD, Devictor V, Green RE, Vorisek P, Strien AV \& Couvet D (2010) Population trends of European common birds are predicted by characteristics of their climatic niche. Global Change Biology, 16(2), pp. 497-505.

Keith D, Akcakaya H, Thuiller W \& Midgley G (2008) Predicting extinction risks under climate change: coupling stochastic population models with dynamic bioclimatic habitat models. Biology Letters, 5, pp. 560-563.

Knutti R, Reinhard F, Tebaldi C, Cermak J \& Meehl G (2010) Challenges in Combining Projections from Multiple Climate Models. J. Climate, 23, pp. 2739-2758.

Koons DN, Pavard S, Baudisch A \& Metcalf CJE (2009) Is life-history buffering or lability adaptive in stochastic environments? Oikos, 118(7), pp. 972-980.

Lack D (1966) Population Studies of Birds (ed Lack D), Oxford University Press. 
Lande R, Engen S \& Saether B (2003) Stochastic Population Dynamics in Ecology and Conservation. Oxford University Press, Oxford.

Lee DE, Nur N \& Sydeman WJ (2007) Climate and demography of the planktivorous Cassins auklet Ptychoramphus aleuticus off northern California: implications for population change. Journal of Animal Ecology, 76(2), pp. 337-347.

Lefebvre W \& Goosse H. (2007). Analysis of the projected regional sea-ice changes in the Southern Ocean during the twenty-first century. Climate Dynamics, 30(1), pp. 5976.

Lindström J \& Forchhammer C (2010) Effects of climate change on birds (eds Møller A, Fiedler W \& Berthold P), Oxford University Press, chapter Time-series analyses., pp. $57-67$.

Massom R, Hill K, Barbraud C, Adams N, Ancel A, Emmerson L \& Pook M (2009) Fast ice distribution in Adélie Land, East Antarctica: interannual variability and implications for emperor penguins Aptenodytes forsteri. Marine Ecology Progress Series, 374, pp. $243-257$.

Mastrandrea M, Field C, Stocker T et al. (2010) Guidance Note for Lead Authors of the IPCC Fifth Assessment Report on Consistent Treatment of Uncertainties. Technical report, Intergovernmental Panel on Climate Change (IPCC), Available at http://www . ipcc.ch.

Mastrandrea MD \& Mach KJ (2011) Treatment of uncertainties in IPCC Assessment Reports: past approaches and considerations for the Fifth Assessment Report. Climatic Change, 108(4), pp. 659-673.

McGowan CP, Runge MC \& Larson MA (2011) Incorporating parametric uncertainty into population viability analysis models. Biological Conservation, 144(5), pp. 1400-1408.

Meehl GA, Covey C, Delworth T et al. (2007) The WCRP CMIP3 multi-model dataset: A new era in climate change research. Bulletin of the American Meteorological Society, $\mathbf{8 8}$, pp. $1383-1394$. 
Mihoub J-B, Gimenez O, Pilard P \& Sarrazin F (2010) Challenging conservation of migratory species: Sahelian rainfalls drive first-year survival of the vulnerable Lesser Kestrel Falco naumanni. Biological Conservation, 143(4), pp. 839-847.

Milner-Gulland EJ (2012) Interactions between human behaviour and ecological systems. Phil. Trans. R. Soc. B,367, pp. 270-278.

Møller A, Fiedler W \& Berthold P (2004) Birds and Climate Change. Vol. Advances in Ecological Research (ed Caswell H), Elsevier Academic Press.

Møller A, Fiedler W \& Berthold P eds. (2010) Effects of climate change on birds. Oxford University Press.

Møller A \& Fiedler W (2010a) Long-term time series of ornithological data. Effects of climate change on birds (eds Møller A, Fiedler W \& Berthold P), Oxford University Press, pp. 33-39.

Monahan WB \& Tingley, MW (2012) Niche tracking and rapid establishment of distributional equilibrium in the House Sparrow show potential responsiveness of species to climate change. PLoS ONE, 7(7): e42097.

Moran PAP (1953) The statistical analysis of the Canadian lynx cycle. II. Synchronization and meteorology. Australian Journal of Zoology, 1, pp. 291-298.

Moreno J \& Møller, AP (2011) Extreme climatic events in relation to global change and their impact on life histories. Current Zoology, 57(57), pp. 375-389.

Morris WF \& Doak DF (2002) Quantitative Conservation Biology. Sinauer Associates, Inc. Publishers, Sunderland, MA.

Morris W, Pfister C, Tuljapurkar S, Haridas C, Boggs CL, Boyce M, Bruna E, Church D, Coulson T, Doak D, Forsyth D, Gaillard J, Horvitz C, Kalisz S \& Kendall B (2008) Longevity can buffer plant and animal populations against changing climate variability. Ecology, 89, pp. 19-25.

Moss RH, Edmonds JA, Hibbard KA et al. (2010) The next generation of scenarios for climate change research and assessment. Nature, 463(7282), pp. 747-756. 
Nevoux M, Barbraud J \& Barbraud C (2008) Breeding experience and demographic response to environmental variability in the White Stork. Condor, 110(1), pp. 55-62.

Nevoux M, Forcada J, Barbraud C, Croxall J \& Weimerskirch H (2010) Bet-hedging response to environmental variability, an intraspecific comparison. Ecology, 91(8), pp. 2416-2427.

Nevoux M, Weimerskirch H \& Barbraud C (2007) Environmental variation and experiencerelated differences in the demography of the long-lived black-browed albatross. Journal of Animal Ecology, 76(1), pp. 159-167.

Newton I (1998) Population Limitation In Birds, Academic Press, San Diego.

Nur NL, Salas S, Veloz J, Wood L, Liu, and Ballard G (2012) Assessing vulnerability of tidal marsh birds to climate change through the analysis of population dynamics and viability. Technical Report. Version 1.0. Report to the California Landscape Conservation Cooperative, PRBO Conservation Science, Petaluma, CA, USA.

Oro D, Torres R, Rodriguez C \& Drummond H (2010) Climatic influence on demographic parameters of a tropical seabird varies with age and sex. Ecology, 91, pp. 1205-1214.

Pascarella JB \& Horvitz C (1998). Hurricane disturbance and the population dynamics of a tropical understory shrub: megamatrix elasticity analysis. Ecology, 79(2), pp. 547-563.

Pardo D, Barbraud C, Authier M \& Weimerskirch H (2012) Evidence for an age-dependent influence of environmental variations on a long-lived seabird's life-history traits. Ecology, in press.

Parmesan C (2006) Ecological and Evolutionary Responses to Recent Climate Change. Annual Review of Ecology, Evolution, and Systematics, 37(1), pp. 637-669.

Parry M, Canziani O, Palutikof J, van der Linden P \& Hanson C (2007) Contribution of Working Group II to the Fourth Assessment Report of the Intergovernmental Panel on Climate Change (eds Parry M, Canziani O, Palutikof J, van der Linden P \& Hanson C), Cambridge University Press, Cambridge, United Kingdom and New York, NY, USA.

Pascarella JB \& Horvitz C. (1998). Hurricane disturbance and the population dynamics of a tropical understory shrub: megamatrix elasticity analysis. Ecology, 79(2), pp. 547563. 
Peach W, Baillie S \& Underhill L (1991) Survival of British sedge warblers Acrocephalus schoenobaenus in relation to west African rainfall. Ibis, 133, pp. 300-305.

Pelletier F, Garant D \& Hendry A. (2009). Eco-evolutionary dynamics. Philosophical Transactions B. 364, pp. 1483-1489

Perrins CM, Lebreton J \& Hirons G (1991) Bird population studies: relevance to conservation and management (eds Perrins CM, Lebreton J \& Hirons G), Oxford University Press, Oxford.

Peery MZ, Gutierrez RJ, Kirby R, Ledee OE \& Lahaye W (2012) Climate change and spotted owls: potentially contrasting responses in the Southwestern United States. Global Change Biology, 18(3), pp. 865-880.

Pierce DW, Barnett TP, Santer BD, \& Gleckler PJ (2009). Selecting global climate models for regional climate change studies. Proceedings of the National Academy of Sciences. 106, pp. 8441-8446

Quintero \& Wiens (2012) What determines the climatic niche width of species? The role of spatial and temporal climatic variation in three vertebrate clades. Global Ecology and Biogeography, early view online.

Racherla PN \& Shindell DT (2012). The added value to global model projections of climate change by dynamical downscaling: A case study over the continental U.S. using the GISS-ModelE2 and WRF models Journal of Geophysical Research, 117, pp. 1-8

Reed T, Schindler, D.E, \& Waples R.S. (2010) Interacting Effects of Phenotypic Plasticity and Evolution on Population Persistence in a Changing Climate. Conservation Biology , 25), pp. 56-63.

Reed T, Jenouvrier S \& Visser M (2012) Phenological mismatch strongly affects individual fitness but not population demography in a woodland passerine. Journal of Animal Ecology.

Ruete A, Yang W, Barring L, Stenseth NC \& Snall T (2012) Disentangling effects of uncertainties on population projections: climate change impact on an epixylic bryophyte. 
Proceedings of The Royal Society B-Biological Sciences, pp. 1-9.

Royama T (1992) Analytical Population Dynamics, Chapman \& Hall, London.

Sæther B-E (2000) Weather Ruins Winter Vacations. Science, 288(5473), pp. 1975-1976.

Sæther B \& Bakke O (2000) Avian life history variation and contribution of demographic trait to the population growth rate. Ecology, 81, pp. 642-653.

Sæther B \& Engen S (2010) Effects of climate change on birds, (eds Møller A, Fiedler W \& Berthold P), chapter Population analyses, pp. 67-77, Oxford University Press.

Sæther B, Grøtan V, Engen S, Noble DG \& Freckleton RP (2009) Critical parameters for predicting population fluctuations of some British passerines. J Anim Ecology, 78(5), pp. 1063-1075.

Sæther B, Sutherland WJ \& Engen S. (2004) Birds and climate change. Advance in ecological research (eds Møller, A, Fielder W et al.) chapter Climate influence on avian population dynamics, pp. 185-205.

Sæther B, Tufto J, Engen S, Jerstad K, Rostad O \& Skatan J (2000a) Population Dynamical Consequences of Climate Change for a Small Temperate Songbird. Science, 287, pp. $854-856$.

Sandvik H, Coulson T \& Sæther B (2008) A latitudinal gradient in climate effects on seabird demography: results from interspecific analyses. Global Change Biology, 14, pp. 703-713.

Sandvik H, Erikstad K \& Sæther B (2012) Climate affects seabird population dynamics both via reproduction and adult survival. Marine Ecology Progress Series, 454, pp. 273-284.

Schaub M, Kania W \& Koppen U (2005) Variation of primary production during winter induces synchrony in survival rates in migratory white storks Ciconia ciconia. Journal of Animal Ecology, 74(4), pp. 656-666.

Schippers P, Verboom J, Vos CC, Jochem R (2011) Metapopulation shift and survival of woodland birds under climate change: will species be able to track? Ecography, 34, pp. 909-919.

Seavy N, Dybala KE \& Snyder MA (2008) Climate Models and Ornithology. Auk, pp. 1-11. 
Sillett T, Holmes R \& Sherry T (2000) Impacts of a global climate cycle on population dynamics of a migratory songbird. Science, 288(5473), pp. 2040-2042.

Small-Lorenz S. L., Culp L. A., Ryder T. B., Will T. C., \& Marra P. P. (2013). A blind spot in climate change vulnerability assessments. Nature Climate Change, 3, pp. 91-93.

Smetacek V \& Nicol S (2005) Polar ocean ecosystems in a changing world. Nature, 437, pp. 362-368.

Solomon S, Qin D, Manning M et al. (2007) Climate Change 200\%: The Physical Science Basis (eds Solomon S, Qin D, Manning M), Contribution of Working Group I to the Fourth Assessment Report of the Intergovernmental Panel on Climate Change, Cambridge University Press, Cambridge, United Kingdom and New York, NY, USA.

Stenseth, N, Mysterud, A, Ottersen G, Hurrell JW, Chan KS \& Lima M. (2002), Ecological Effects of Climate Fluctuations, Science, 297, pp. 1292-1296.

Stenseth N, Ottersen G, Hurrell JW et al. (2003) Studying climate effects on ecology through the use of climate indices, the North Atlantic Oscillation, El Niño Southern Oscillation and beyond. Proceedings of the Royal Society of London B, pp. 2087-2096.

Stock CA, Alexander MA, Bond NA et al. (2011) On the use of IPCC-class models to assess the impact of climate on Living Marine Resources. Progress in Oceanography, 88(1-4), pp. $1-27$.

Stralberg D, Brennan M, Callaway JC et al. (2011) Evaluating tidal marsh sustainability in the face of sea-level rise: A Hybrid modeling approach applied to San Francisco Bay. PloS ONE, 6(11): e27388. doi:10.1371/journal.pone.0027388.

Sutherland WJ \& Freckleton RP (2012) Making predictive ecology more relevant to policy makers and practitioners. Philosophical Transactions of the Royal Society B: Biological Sciences, 367(1586), pp. 322-330.

Sydeman W, Thompson S \& Kitaysky A (2012) Seabirds and climate change: roadmap for the future. Marine Ecology Progress Series, 454, pp. 1-203. 
Tebaldi C \& Knutti R (2007) The use of the multi-model ensemble in probabilistic climate projections. Philosophical Transactions of the Royal Society A, pp. 1-24.

Thaxter CB, Joys AC, Gregory RD, Baillie SR \& Noble DG (2010) Hypotheses to explain patterns of population change among breeding bird species in England. Biological Conservation, 143(9), pp. 2006-2019.

Thomas D \& Dieckmann G (2003) Sea ice: an introduction to its physics, chemistry, biology and geology. (eds Thomas D \& Dieckmann G) Oxford: Blackwell Science.

Thomas, C. D.; Cameron, A.; Green, R. E. \& al. (2004) Extinction risk from climate change. Nature 427: 145-148.

Thompson P \& Ollason J (2001) Lagged effects of ocean climate change on fulmar population dynamics. Nature, 413(6854), pp. 417-420.

Thomson DL, Cooch EG \& Conroy MJ (2009) Modelling demographic processes in marked populations. Springer, New York.

Tingley MW, Monahan WB, Beissinger SR and Moritz C (2009) Birds track their Grinnellian niche through a century of climate change. Proceedings of the National Academy of Sciences USA, 106, pp. 19637-19643.

Trivelpiece WZ, Hinke JT, Miller AK, Reiss CS, Trivelpiece SG \& Watters GM (2011) From the Cover: Variability in krill biomass links harvesting and climate warming to penguin population changes in Antarctica. Proceedings of the National Academy of Sciences, 108(18), pp. 7625-7628.

Tuljapurkar S \& Horvitz C (2006) From stage to age in variable environments: life expectancy and survivorship. Ecology, 87(6), pp. 1497-1509.

Tuljapurkar S, Horvitz CC \& Pascarella JB (2003) The many growth rates and elasticities of populations in random environments. American Naturalist, 162, pp. 489-502.

van de Pol M, Vindenes Y, Saether B-E, Engen S, Ens BJ, Oosterbeek K \& Tinbergen JM (2010) Effects of climate change and variability on population dynamics in a long-lived shorebird. Ecology, 91(4), pp. 1192-1204. 
van Vuuren DP, Edmonds J, Kainuma M et al. (2011) The representative concentration pathways: an overview. Climatic Change, 109, pp. 5-31.

Vargas FH, Lacy R, Johnson PJ, Steinfurthe A, Crawfordf R, Boersma PD \& Macdonald DW (2007) Modelling the effect of El Niño on the persistence of small populations: The Galapagos penguin as a case study. Biological Conservation, 137, pp. 138-148.

Visser ME (2008) Keeping up with a warming world; assessing the rate of adaptation to climate change. Proceedings of the Royal Society B: Biological Sciences.

Visser M, Adriaensen F, van Balen J et al. (2003) Variable responses to large-scale climate change in European Parus population. Proceedings of the Royal Society of London.B., 270, pp. 367-372.

Visser M \& Both C (2005) Review. Shifts in phenology due to global climate change: the need for a yardstick. Proceedings of the Royal Society B: Biological Sciences, 272(1581), pp. $2561-2569$.

Visser, M, Both C \& Lambrechts M (2004) Global climate change leads to mistimed avian reproduction. Advance in ecological research, 35, pp. 89-110.

Visser M, van Noordwijk AJ, Tinbergen J \& Lessells C (1998) Warmer springs lead to mistimed reproduction in great tits (Parus major). Proceedings of the Royal Society B: Biological Sciences, 265, pp. 1867-1870.

Walther G, Post E, Convey P et al. (2002), Ecological responses to recent climate change. Nature, 416, pp. 389-395.

Weigel AP, Knutti R, Liniger MA \& Appenzeller C. (2010). Risks of Model Weighting in Multimodel Climate Projections. Journal of Climate, 23(15), pp. 41754191.

Weimerskirch H, Inchausti P, Guinet C \& Barbraud C (2003) Trends in bird and seal populations as indicators of a system shift in the southern ocean. Antarctic Science, 15, pp. 249-256.

Weimerskirch H, Louzao M, de Grissac S \& Delord K (2012) Changes in Wind Pattern Alter Albatross Distribution and Life-History Traits. Science, 335(6065), pp. 211-214. 
Williams BK, Nichols JD \& Conroy MJ (2002) Analysis and management of animal populations. Academic Press, San Diego, p. 817.

Wolf SG, Snyder MA, Sydeman WJ, Doak DF \& Croll DA (2010) Predicting population consequences of ocean climate change for an ecosystem sentinel, the seabird Cassins auklet. Global Change Biology, 16(7), pp.1923-1935.

Wormworth J \& Şekercioğlu C (2011) Winged sentinels: Birds and climate change (eds Wormworth J \& Şekercioğlu C), Cambridge University Press.

Zeigler, S. (2013). Predicting responses to climate change requires all life-history stages. Journal of Animal Ecology, 82, pp. 3-5.

\section{Table}

\section{$9 \quad$ Figure}

\section{Figure}

Figure1: Description of the processes by which climate affects population. Population size, growth and structure is driven by change in vital rates (e.g. reproduction, growth and survivorship; orange box), as well as immigration and emigration (not shown). Birds' vital rates can be affected by changing climate conditions directly or indirectly through impact on their breeding habitat (green box) or through changes in their food supply/food availability (grey boxes). The amount of food obtained by a bird depends on its foraging behaviors. These acquisition processes are represented in purple and affect the individual's vital rates (orange boxes). Allocation processes (red) describe how the energy is allocated according to tradeoffs between reproduction, growth and survivorship. Finally, population density may

affect the food supply/food availability and quality/ availability of breeding habitat through intra- specific competition. Among many other factors, these density dependence effects may thus interact with climate impact. Individual heterogeneity in life history traits caused by, e.g. age, sex or experience, is not shown, but also plays an important role in shaping 
Table 1: Projections of avian population's responses to climate change using information from IPCC- class models.

\begin{tabular}{|c|c|}
\hline Species & Climate \\
\hline $\begin{array}{l}\text { Snowy Plover } \\
\text { Florida } \\
\text { (Aiello-Lammens et al. } \\
\text { 2011) }\end{array}$ & $\begin{array}{l}1 \text { mid-level SRES }{ }^{\star} \text {; } \\
1 \text { regional model; } \\
\text { determinist predictions of sea-level } \\
\text { rise }\end{array}$ \\
\hline $\begin{array}{l}\text { Adélie and Emperor } \\
\text { penguins } \\
\text { Antarctica } \\
\text { (Ainley et al. 2010) }\end{array}$ & $\begin{array}{l}1 \text { mid-level SRES; } \\
\text { selection among } 18 \text { AOGCMs; } \\
\text { deterministic prediction of sea } \\
\text { ice coverage and thickness, wind } \\
\text { speeds, precipitation, and air tem- } \\
\text { peratures }\end{array}$ \\
\hline
\end{tabular}

Albatrosses and petrels

Southern Ocean

(Barbraud et al. 2010)

Four duck species

Western boreal forest

of North America

(Drever et al. 2011)

Emperor Penguin

Antarctica

(Jenouvrier et al.

2009)

(Jenouvrier et al.

2012)

Tidal Marsh Song Sparrows

San Francisco Estuary

(Nur et al. 2012)

\section{three SRES;}

selection among 18 AOGCMs;

deterministic predictions of sea surface temperature and sea ice extent

1 pessimistic SRES;

8 AOGCMs;

stochastic predictions of spring snow cover duration

1 mid-level SRES;

selection among 20 AOGCMs; stochastic predictions of years with lower sea ice extent

1 mid-level SRES;

selection among 20 AOGCMs; stochastic predictions of sea ice concentration

1 mid-level SRES;

2 regional models;

stochastic forecasts of temperature and precipitation; scenarios of sealevel rise / extreme tides / nest management quasi-extinction probability

Southwestern USA

(Peery et al. 2012)

Eurasian

Oystercatcher

Netherlands

(van de Pol et al. 2010)

Cassins Auklet

California

(Wolf et al. 2010) three SRES*;

4 AOGCMs;

stochastic forecasts of temperature and precipitation

four scenarios;

1 regional model;

stochastic predictions of temperature

1 mid-level SRES;

1 regional model;

deterministic sea surface tempera-

ture and upwelling intensity population trajectories and
Population

stochastic predictions of population trajectories, quasiextinction probability ${ }^{\bullet}$ based on habitat availability

anticipate population trends based on habitat availability

stochastic prediction of
population trajectories,
quasi-extinction time and quasi-extinctio
probability

stochastic forecasts of mean population size

stochastic predictions of population trajectories and quasi-extinction probability

stochastic predictions of population trajectories and quasi-extinction probability

stochastic predictions of population trajectories and quasi-extinction probability

stochastic predictions of population trajectories and

Conclusion

up to $25 \%$ quasi-extinction probability; decline of carrying capacity by $\sim 35 \%$

By global average air temperature reaches $2{ }^{\circ} \mathrm{C}$ above preindustrial levels: anticipated decline of colonies north of $70^{\circ} \mathrm{CS}(\sim 50 \%$ of Emperor colonies and $\sim 75 \%$ of Adélie colonies).

Extinction of the Black-browed Albatross population; Increase of Amsterdam

Albatross population; snow petrel - $1 \%$ change in mean stochastic $\lambda$ between present and 2075-2100.

median of relative proportional change: increase up to $8.1 \%$ for mallard; decline up to $-12.4 \%$ for american pigeon, $-12.9 \%$ for scaup, $-31 \%$ for scoter

The median population size is predicted to decline to 400 breeding pairs

The median population size is predicted to decline to 575 breeding pairs

Quasi-extinction probability vary from $2 \%$ for a low sea-level rise scenario up to $60 \%$ for high sea-level rise. Occurrence of infrequent extreme tides more than doubled the quasi-extinction probability from $12 \%$ to $28 \%$ for the medium sea-level rise scenario. Nests management actions can arrest and even reversing these anticipated declines.

Quasi-extinction probability are up to 99 and $94 \%$ for populations at Arizona and New Mexico; no extinction for Southern California population

stochastic predictions of population trajectories and

Shift from extinction to stationary fluctuations around a mean population size

stochastic predictions of population growth rate
Up to 0.447 absolute change in mean 1980-1999 and 2080-2099 stochastic population growth rate between

* SRES is a Special Report on Emissions Scenarios by the IPCC describing greenhouse gas emissions scenarios making different assumptions for future greenhouse gas pollution, land-use and other driving forces using assumptions about future technological development as well as the future economic development.

- Quasi-extinction probability are defined as a probability of a population decline by $x \%$ or more by $2100 ; x$ being defined by each study differently.

$\lambda$ is the population growth rate.

Anticipating refers to projection based on fact and qualitative expert judgment; forecasting to projection obtained with time series statistical projections and predicting to projection using some level of our understanding of causal mechanisms underlying climate or population processes using mathematical models. 
acquisition and allocation processes, hence vital rates and population responses to climate. Figure 2: Impact of extreme harsh winters on the vital rates (survival and brood size) and stochastic population growth rate of the Barn Owl (Tyto alba). Survival and brood size times series are from Altwegg et al. (2006), and red arrows indicate two extreme winters with the longest snow cover. These extreme events correspond to very rare events (3.5th percentile of the distribution). Appendix 1 describes the population model dependent of extreme harsh winters used to predict the impact of an increase frequency of extreme events on Barn Owl stochastic growth rate.

Figure 3: Description of the "population robustness to climate change". The "population robustness to climate change" is represented by the yellow area. It is a measure combining the range of climatic conditions where the population is capable of increase (i.e. where the intrinsic population rate of increase is positive, noted as $C_{a}^{*}$, green arrow) and the magnitude of how fast a population can grow within $C_{a}^{*}$ (e.g. noted $r^{*}$, red arrow, for the optimal $C_{a}$ ). Eury- species (wide $C_{a}^{*}$, left panels) may cope better with future climate change than steno- species (narrow $C_{a}^{*}$, right panels) because they may have a greater chance of having a population that may grow under shifting climate conditions. In addition populations with a greater magnitude of positive growth rate for a given climate condition (upper panels) can withstand higher population growth reduction caused by other perturbations (climatic or not) than populations with a limited growth (lower panels).

Figure 4: Projections of the Emperor Penguin population based on sea ice concentration predictions from a multi-model ensemble of five AOGCMs and a mid-level range climate scenario. The black line gives the observed number of breeding pairs from 1979 to 2010. (a) For each AOGCM, the median are shown (thick colored line); the median and 95\% envelope (grey area) of the ensemble are shown from the combined 200,000 simulations for the set of 5 GCMs, which include demographic and climate uncertainties. (b) Comparison of the median and $95 \%$ envelope (grey area) for the ensemble and median and $95 \%$ envelope (dotted lines) using a linear climate forecast. The linear climate forecast is obtained using the mean 
SIC predicted by an ensemble of AOGCMs by 2100 (estimates from Lefevre \& Goose 2009) and projecting a linear trend from 2010 to 2100. Stochastic SIC forecasts are obtained by sampling at each time $t$ into a normal distribution of mean $\mu_{t}$ and variance $\sigma_{t} . \mu_{t}$ is estimated from the linear trend, and $\sigma_{t}$ is either the observed variability (calculated from observed data) or the predicted variability (estimates from Lefevre \& Goose 2009). (c) Comparison of the median and 95\% envelope (grey area) for the ensemble and the median and 95\% envelope (dotted lines) from the average of the ensemble. The average of the ensemble, provide better projections of the current forced climate change because this averaging procedure hides the errors from individual models. However, ecologists rarely calculate the variance of the average of the ensemble and thus ignore the full range of natural variability.

Figure 5: Description of the various sources of uncertainties, which can be incorporated using a hierarchical process. Colored circles represent the various replication loops of the model. Prediction uncertainty in the climate scenario (or other future driver scenario) is incorporated into the first replication loop. Climate initial conditions, structural model uncertainty and parameter uncertainty are included into a second loop by using a multi-model ensemble of AOGCMs. Climate natural variability using stochastic climate forecast appears in the third loop. Demographic initial conditions, parametric and model structural uncertainties are incorporated into the fourth replication loop, while environmental stochasticity is incorporated into the fifth loop for time steps in the model. Finally, demographic stochasticity simulates the fates of individual organisms within a particular time step and replicate into an inner loop (the individual loop). 


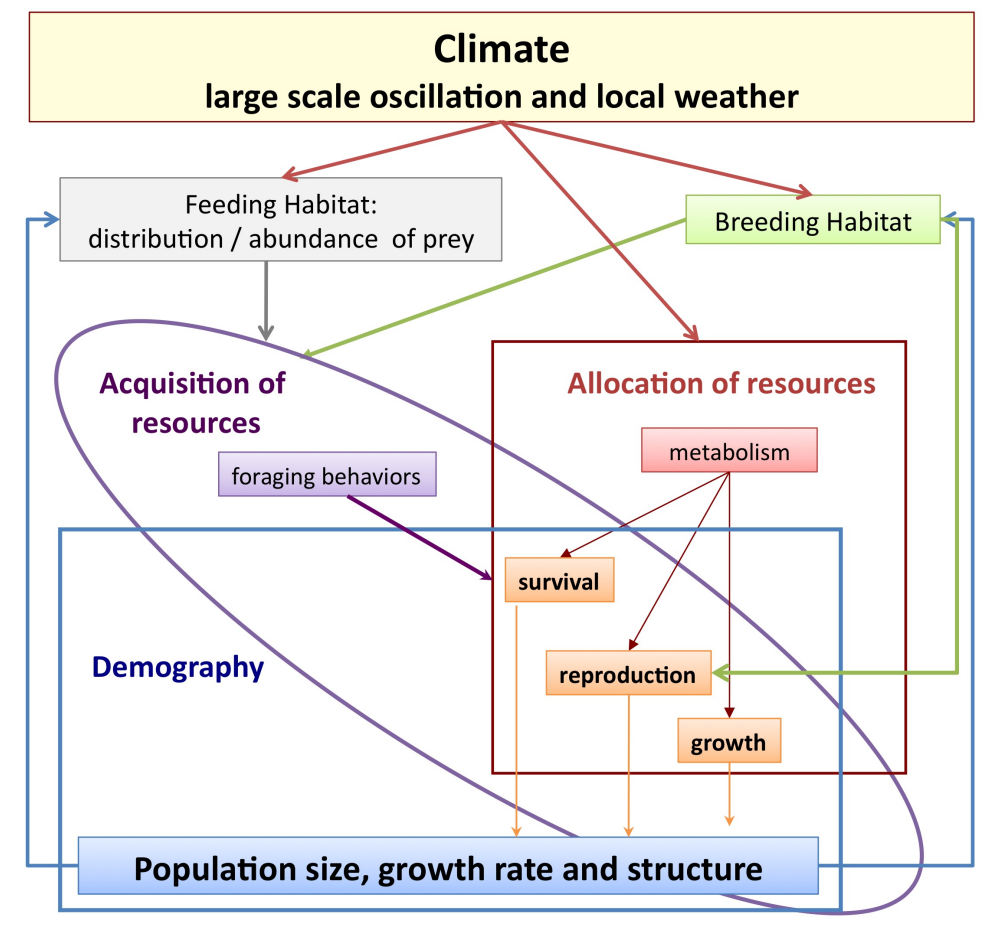

Figure 1: Description of the processes by which climate affects population. Population size, growth and structure is driven by change in vital rates (e.g. reproduction, growth and survivorship; orange box), as well as immigration and emigration (not shown). Birds' vital rates can be affected by changing climate conditions directly or indirectly through impact on their breeding habitat (green box) or through changes in their food supply/food availability (grey boxes). The amount of food obtained by a bird depends on its foraging behaviors. These acquisition processes are represented in purple and affect the individual's vital rates (orange boxes). Allocation processes (red) describe how the energy is allocated according to tradeoffs between reproduction, growth and survivorship. Finally, population density may affect the food supply/food availability and quality/ availability of breeding habitat through intra- specific competition. Among many other factors, these density dependence effects may thus interact with climate impact. Individual heterogeneity in life history traits caused by, e.g. age, sex or experience, is not shown, but also plays an important role in shaping acquisition and allocation processes, hence vital rates and population responses to climate. 


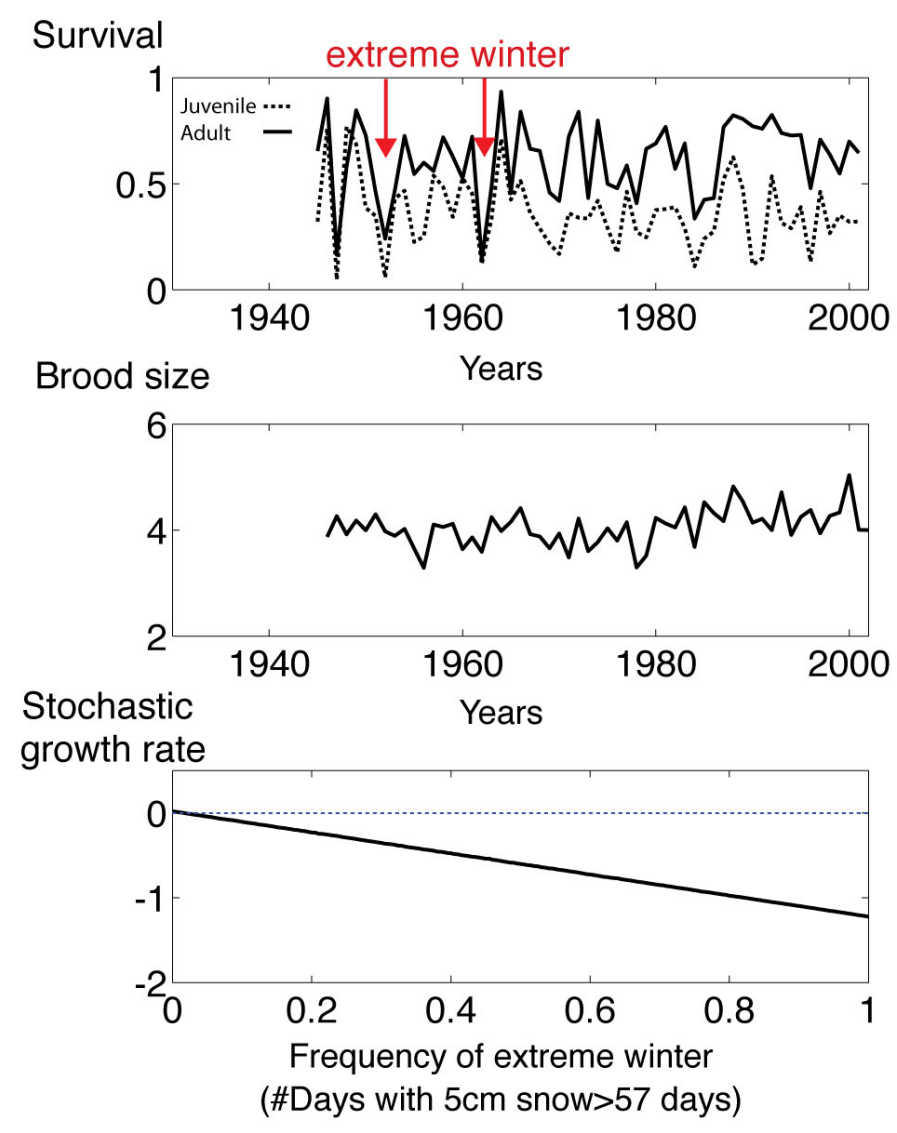

Figure 2: Impact of extreme harsh winters on the vital rates (survival and brood size) and stochastic population growth rate of the Barn Owl (Tyto alba). Survival and brood size times series are from Altwegg et al. (2006), and red arrows indicate two extreme winters with the longest snow cover. These extreme events correspond to very rare events (3.5th percentile of the distribution). Appendix 1 describes the population model dependent of extreme harsh winters used to predict the impact of an increase frequency of extreme events on Barn Owl stochastic growth rate. 


\section{Population robustness to climate change}

Intrinsic population rate of increase corrected by life expectancy
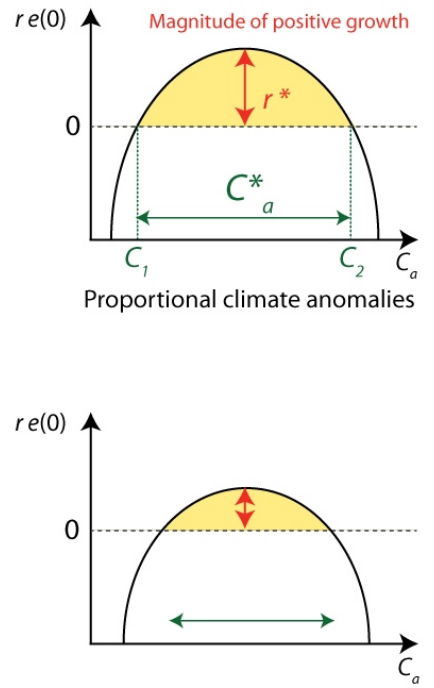

Eury- species
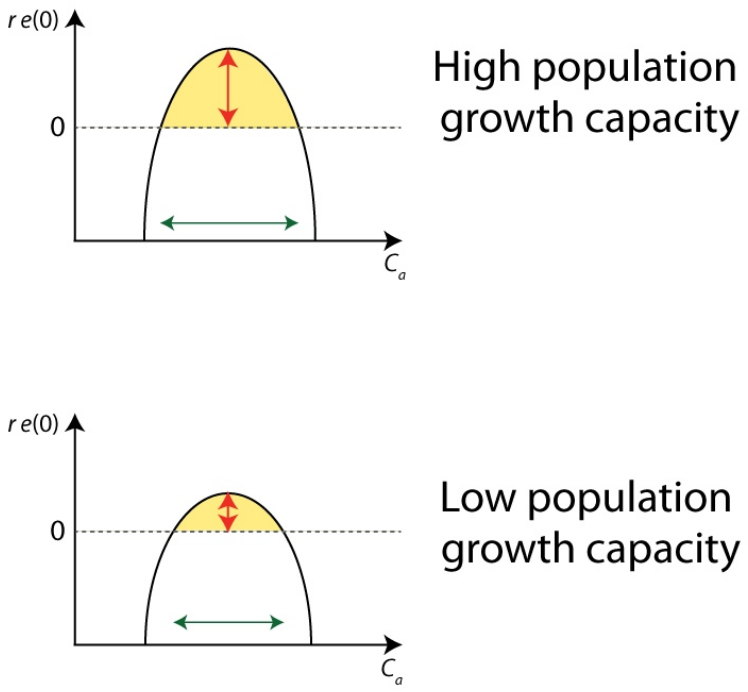

Low population growth capacity

Steno- species

Figure 3: Description of the "population robustness to climate change". The "population robustness to climate change" is represented by the yellow area. It is a measure combining the range of climatic conditions where the population is capable of increase (i.e. where the intrinsic population rate of increase is positive, noted as $C_{a}^{*}$, green arrow) and the magnitude of how fast a population can grow within $C_{a}^{*}$ (e.g. noted $r^{*}$, red arrow, for the optimal $C_{a}$ ). Eury- species (wide $C_{a}^{*}$, left panels) may cope better with future climate change than steno- species (narrow $C_{a}^{*}$, right panels) because they may have a greater chance of having a population that may grow under shifting climate conditions. In addition populations with a greater magnitude of positive growth rate for a given climate condition (upper panels) can withstand higher population growth reduction caused by other perturbations (climatic or not) than populations with a limited growth (lower panels). 

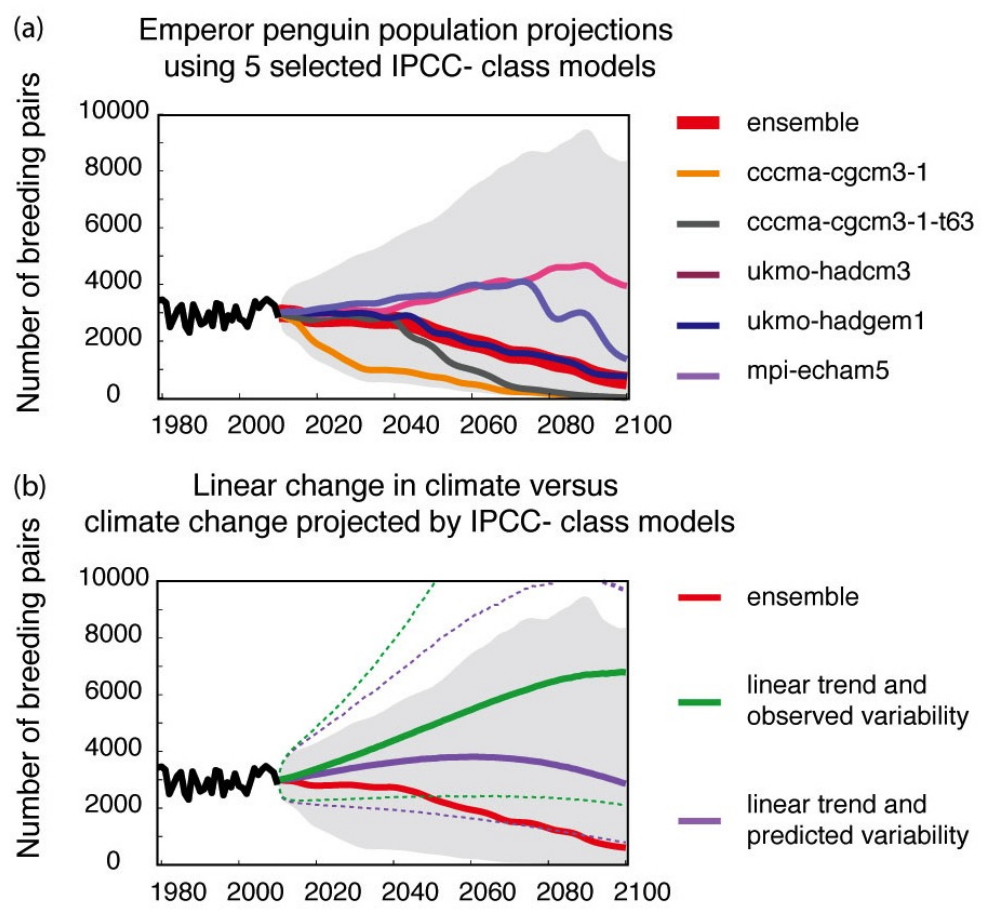

(c) Forced change versus

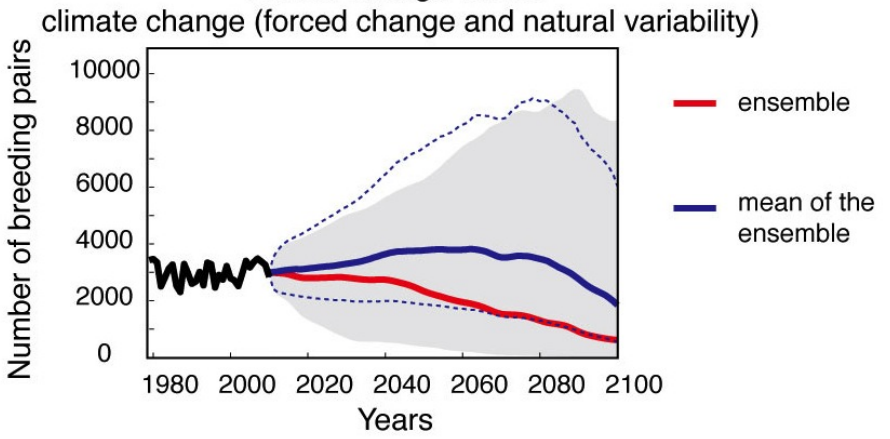

Figure 4: Projections of the Emperor Penguin population based on sea ice concentration predictions from a multi-model ensemble of five AOGCMs and a mid-level range climate scenario. The black line gives the observed number of breeding pairs from 1979 to 2010. (a) For each AOGCM, the median are shown (thick colored line); the median and 95\% envelope (grey area) of the ensemble are shown from the combined 200,000 simulations for the set of $5 \mathrm{GCMs}$, which include demographic and climate uncertainties. (b) Comparison of the median and 95\% envelope (grey area) for the ensemble and median and 95\% envelope (dotted lines) using a linear climate forecast. The linear climate forecast is obtained using the mean SIC predicted by an ensemble of AOGCMs by 2100 (estimates from Lefevre \& Goose 2009) and projecting a linear trend from 2010 to 2100 . Stochastic SIC forecasts are obtained by sampling at each time $t$ into a normal distribution of mean $\mu_{t}$ and variance $\sigma_{t} . \mu_{t}$ is estimated from the linear trend, and $\sigma_{t}$ is either the observed variability (calculated from observed data) or the predicted variability (estimates from Lefevre \& Goose 2009). (c) Comparison of the median and 95\% envelope (grey area) for the ensemble and the median and 95\% envelope (dotted lines) from the average of the ensemble. The average of the ensemble, provide better projections of the current forced climate change because this averaging procedure hides the errors from individual models. However, ecologists rarely calculate the variance of the average of the ensemble and thus ignore the full range of natural variability. 


\section{Hierarchical process Various sources of uncertainties}

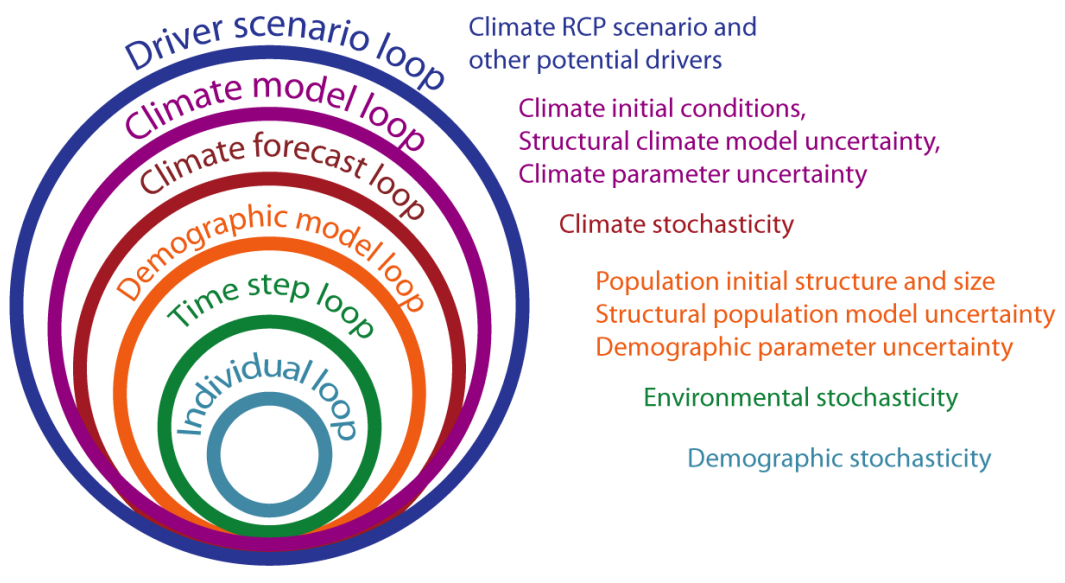

Figure 5: Description of the various sources of uncertainties, which can be incorporated using a hierarchical process. Colored circles represent the various replication loops of the model. Prediction uncertainty in the climate scenario (or other future driver scenario) is incorporated into the first replication loop. Climate initial conditions, structural model uncertainty and parameter uncertainty are included into a second loop by using a multi-model ensemble of AOGCMs. Climate natural variability using stochastic climate forecast appears in the third loop. Demographic initial conditions, parametric and model structural uncertainties are incorporated into the fourth replication loop, while environmental stochasticity is incorporated into the fifth loop for time steps in the model. Finally, demographic stochasticity simulates the fates of individual organisms within a particular time step and replicate into an inner loop (the individual loop). 


\section{Supplementary Appendix 1: Impact of extreme harsh winters on the demography of the Barn Owl.}

I used the exceptional long- term survival and brood size time series of the Barn Owl (Tyto alba) from 1945 to 2002 described in Altwegg et al. (2006). Those vital rates were digitalized from Altwegg et al. (2006)'s Figure 1. Stochastic population growth rate was calculated using the stage structured matrix population model described in Altwegg et al. (2006) and by constructing a two- states matrix climate- dependent model. Such models have been used frequently, as in studies of fire (Caswell \& Kaye 2001) and hurricanes (Pascarella \& Horvitz 1998).

The annual life cycle includes two stages: adults and juveniles (Altwegg et al. 2006). The matrix population model (Caswell 2001) projects the population from time $t$ to $t+1$ by

$$
\mathbf{n}_{t+1}=\mathbf{A}_{t} \mathbf{n}_{t}
$$

where $n_{i}$ is the abundance of stage $i$, and $\mathbf{A}_{t}$ is the population projection matrix at time $t$, which contains the vital rates for the two respective stages.

The two- states climate- dependent model considers a climate in which normal and extreme harsh winter years occur independently, with probability $p$ of an extreme year and $1-p$ of a normal year. $p$ is thus the frequency of extreme winters, defined as the event when the number of days with $5 \mathrm{~cm}$ snow cover is more than 57 days. In a an extreme year, the projection matrix $A$ is selected randomly from the matrices for 1952 and 1962 (red arrows on Fig 3, main text); in a normal year, the projection matrix is selected randomly from the matrices for years 1945- 2002, excluding the two extreme years. Note that 1947 was an extreme year in term of Barn Owl demography (extreme lower values for survival) but did not correspond to an extreme harsh winter. Thus it was included as a normal year, in terms of climate. 
The stochastic growth rate is given by

$$
\log \lambda_{s}=\lim _{T \rightarrow \infty} \frac{1}{T} \log \|\mathbf{A}[\boldsymbol{\theta}(T-1)] \cdots \mathbf{A}[\boldsymbol{\theta}(0)] \mathbf{n}(0)\|
$$

with $n(0)$ an arbitrary vector. I evaluated $\log \lambda_{s}$ numerically using $T=200,000$. 


\section{Supplementary Table 1: Prospective analysis for matrix stage structured models}

Although perturbation analysis can be achieved with numerical simulations, analytical frameworks offer a powerful approach. Under the umbrella of matrix stage structured models, Caswell developed an analytical equation for perturbation analysis for a wide range of models from linear to non- linear models, from non-density to density dependent models, and for periodic models (Caswell 2000, 2001, 2005, 2008, 2011, 2012). This Table illustrates how the sensitivity of the population growth rate $\lambda$ can be calculated with respect to any parameter x (e.g. vital rate or climate variables) of the model using derivative chain rule (Caswell 2000, 2001).

Table 2: Tools to study the respective effect of climate variables and vital rates to population growth using matrix models (Caswell 2001). Outputs of the climate-dependent matrix population model and perturbation analysis (i.e. sensitivity analysis). Notation as in Caswell (2007). Matrices in derivatives are vectorized, but for conciseness the vec operator is not explicitly displayed. "wrt" stands for "with respect to".

\begin{tabular}{lll}
\hline Population ecology & Notation & Calculation \\
\hline Population growth rate & $\lambda$ & Dominant eigenvalue of $\mathbf{A}$ \\
Stable stage distribution & $\mathbf{W}$ & Right eigenvector corresponding to $\lambda$ \\
Reproductive value & $\mathbf{V}$ & Left eigenvector corresponding to $\lambda$ \\
Sensitivity of $\lambda$ wrt population matrix $\mathbf{A}$ & $\frac{\partial \lambda}{\partial \mathbf{A}^{\top}}$ & $\frac{\mathbf{v w}^{\top}}{\mathbf{w}^{\top} \mathbf{v}}$ \\
Sensitivity of $\lambda$ wrt vital rate $\boldsymbol{\theta}$ & $\frac{\partial \lambda}{\partial \boldsymbol{\theta}^{\top}}$ & $\frac{\partial \lambda}{\partial \mathbf{A}^{\top}} \frac{\partial \mathbf{A}}{\partial \boldsymbol{\theta}^{\top}}$ \\
& $\frac{\partial \lambda}{\partial \boldsymbol{c}^{\top}}$ & $\frac{\partial \lambda}{\partial \mathbf{A}^{\top}} \frac{\partial \mathbf{A}}{\partial \boldsymbol{\theta}^{\top}} \frac{\partial \boldsymbol{\theta}}{\partial \boldsymbol{c}^{\top}}$ \\
\hline
\end{tabular}

